OPEN ACCESS

Edited by:

Samantha Oester, George Mason University,

United States

Reviewed by:

Federica Rizzetto,

Istituto di Scienze Marine (CNR), Italy

Brett Favaro,

Memorial University of Newfoundland,

Canada

*Correspondence:

Edwin A. Hernández-Delgado

edwin.hernandezdelgado@gmail.com

Specialty section:

This article was submitted to

Marine Conservation and

Sustainability,

a section of the journal

Frontiers in Marine Science

Received: 21 February 2017

Accepted: 19 July 2017

Published: 08 August 2017

Citation:

Otaño-Cruz A, Montañez-Acuña AA,

Torres-López $V$,

Hernández-Figueroa EM and Hernández-Delgado EA (2017) Effects of Changing Weather, Oceanographic

Conditions, and Land Uses on

Spatio-Temporal Variation of

Sedimentation Dynamics along

Near-Shore Coral Reefs.

Front. Mar. Sci. 4:249.

doi: 10.3389/fmars.2017.00249

\section{Effects of Changing Weather, Oceanographic Conditions, and Land Uses on Spatio-Temporal Variation of Sedimentation Dynamics along Near-Shore Coral Reefs}

\author{
Abimarie Otaño-Cruz ${ }^{1,2,3}$, Alfredo A. Montañez-Acuña ${ }^{3}$, Valeria Torres-López ${ }^{3}$, \\ Elix M. Hernández-Figueroa ${ }^{1,2}$ and Edwin A. Hernández-Delgado 1, 2, 3,4* \\ ${ }^{1}$ Department of Environmental Science, University of Puerto Rico, San Juan, Puerto Rico, ${ }^{2}$ Center for Applied Tropical \\ Ecology and Conservation, Coral Reef Research Group, University of Puerto Rico, San Juan, Puerto Rico, ${ }^{3}$ Sociedad \\ Ambiente Marino, San Juan, Puerto Rico, ${ }^{4}$ Department of Biology, University of Puerto Rico, San Juan, Puerto Rico
}

Sedimentation is a critical threat to coral reefs worldwide. Major land use alteration at steep, highly erodible semi-arid islands accelerates the potential of soil erosion, runoff, and sedimentation stress to nearshore coral reefs during extreme rainfall events. The goal of this study was to assess spatio-temporal variation of sedimentation dynamics across nearshore coral reefs as a function of land use patterns, weather and oceanographic dynamics, to identify marine ecosystem conservation strategies. Sediment was collected at a distance gradient from shore at Bahia Tamarindo (BTA) and Punta Soldado (PSO) coral reefs at Culebra Island, Puerto Rico. Sediment texture and composition were analyzed by dry sieving and loss-on-ignition techniques, and were contrasted with environmental variables for the research period (February 2014 to April 2015). Rainfall and oceanographic data were analyzed to address their potential role on affecting sediment distribution with BEST BIO-ENV, RELATE correlation, and linear regression analysis. A significant difference in sedimentation rate was observed by time and distance from shore (PERMANOVA, $p<0.0100$ ), mostly attributed to higher sediment exposure at reef zones closer to shore due to strong relationships with coastal runoff. Sedimentation rate positively correlated with strong rainfall events (Rho $=0.301, p=0.0400$ ) associated with storms and rainfall intensity exceeding $15 \mathrm{~mm} / \mathrm{h}$. At BTA, sediment deposited were mostly composed of sand, suggesting a potential influence of resuspension produced by waves and swells. In contrast, PSO sediments were mostly composed of silt-clay and terrigenous material, mainly attributed to a deforestation event that occurred at adjacent steep sub-watershed during the study period. Spatial and temporal variation of sedimentation pulses and terrigenous sediment input implies that coral reefs exposure to sediment stress is determined by local land use patterns, weather, and oceanographic dynamics. Comprehensive understanding of sediment dynamics and coastal ecosystem interconnectivity is fundamental to implement integrated and adaptive management strategies aimed to promote sustainable development at watershed and 
island wide-scale to fully mitigate terrigenous sediment impact to marine ecosystems. Furthermore, decision-making processes and policy needs to address sedimentation stress in the context of future climate to reduce land-based threats and strengthen coral reef resilience.

Keywords: land use, near-shore coral reefs, precipitation, sediment composition, sediment grain size, sedimentation rate, tropical semi-arid watershed

\section{INTRODUCTION}

Coral reefs are highly productive ecosystems, which provide vital ecological services that sustain human coastal communities' livelihoods (Moberg and Folke, 1999; Roberts et al., 2002; Barbier et al., 2011). Nevertheless, live coral cover decline and coral reef habitat degradation have been documented in the Caribbean region during recent decades (Gardner et al., 2003; Wilkinson and Souter, 2008; Hughes et al., 2010; Jackson et al., 2014). Coral reef degradation has been mainly attributed to a combination of cumulative and synergistic effects from diverse human-induced stressors, including global climate change (Hughes, 1994; Wild et al., 2011; Hernández-Delgado, 2015). Coastal sediment fluxes produced by sediment-laden runoff have been identified as one of the primary causes of coral reef habitat degradation (Rogers, 1990). Sedimentation is a natural process defined as the distribution of unconsolidated particles (derived from terrestrial or marine sources) through fluvial hydrodynamic means that interconnects the terrestrial, coastal, and marine ecosystems (Apitz, 2012). Thus, there is a major concern regarding the potential influence of unsustainable development of arid watersheds and projected climate variability (i.e., increased frequency of extreme rainfall events) on fluvial sediment delivery to nearshore ecosystems of small tropical islands (Brooks et al., 2007; Smith et al., 2008; Hernández-Delgado et al., 2014a).

Trends of unsustainable urban sprawl and deforestation at sensitive coastal areas, such as arid steep slopes, increase watersheds' vulnerability to erosion during extreme rainfall episodes (Nemeth and Sladek, 2001; Hernández-Delgado et al., 2012, 2014a; Ramos-Scharrón et al., 2012; Gellis, 2013; Edmunds and Gray, 2014). Sediment yield and influx from arid coastal watersheds into marine ecosystems vary in response to the watershed's catchment size, slope, land use patterns, and local rainfall volume and intensity (Rogers, 1990; Ramos-Scharrón and MacDonald, 2007; Rodrigues et al., 2013; Browning et al., 2016). In addition, seasonal meteorological and oceanographic forces, which are related to wind, wave and currents, influence local hydronamics, affect sediment distribution along the coastal marine environment (Ogston et al., 2004; Storlazzi et al., 2009). Spatial and temporal sediment dynamics along near-shore coral reefs emphasize existing land-sea and climate interactions. Therefore, to address sediment dynamics it is important to tackle terrestrial impacts, at the watershed scale, of local weather and oceanographic forces.

Elevated suspended sediment loads and accumulation rates have been associated with coral bleaching, partial colony mortality, reduced growth rates, lower coral recruitment rates, declining species diversity, and coral tissue damage (Loya, 1976;
Rogers, 1983, 1990; Cortés and Risk, 1985; Richmond, 1997; Torres and Morelock, 2002; Nugues and Roberts, 2003; Fabricius, 2005). Thus, when sedimentation rates abruptly increase, the ecosystem capacity to adapt and cope with ongoing and further change is compromised (Hughes et al., 2010; Fabricius, 2011). Sedimentation impact on coral reef benthic habitat has been related to the sediment accumulation rates, which in turn have been associated with sediment grain size and composition, and have been identified as key factors that determine sediment distribution and the magnitude of influence on coral reefs health (Nugues and Roberts, 2003; Weber et al., 2006; Fabricius, 2011). Thus, there is a major concern about the effects of sedimentation fluxes along near-shore coral reefs in tropical regions. As extreme rainfall events associated with erosion, runoff and sedimentation stress become more recurrent, coral reefs become more susceptible to phase shifts on their benthic community structure favoring dominance of species resistant to sedimentation (Loya, 1976; Hernández-Delgado et al., 2009; Bégin et al., 2013).

Currently, there is a general lack of quantitative information regarding sediment dynamics along near-shore coral reefs surrounding small semi-arid islands. At the same time, there is a need to understand the effects of changing land uses, local weather, and oceanographic conditions on coastal sediment distribution processes. Understanding the spatial and temporal sediment accumulation rates and sediment properties along targeted restoration sites has the potential to enhance management actions effectiveness in order to prevent further coral reef degradation due to local sedimentation stress. This information is of particular importance when it comes to marine conservation because it can provide the foundation for decision-making regarding integrated watershed and coral reef management aimed to reduce land-based source pollution (LBSP) and coral reef decline.

This study assessed and analyzed sediment spatio-temporal dynamics along two near-shore coral reefs of Culebra Island, Puerto Rico, in the northeastern Caribbean Sea. Culebra's coral reef benthic communities have been recognized to possess high biodiversity and benthic assemblages representative of the northeastern Caribbean region (Hernández-Delgado, 2000, 2003). The island's tropical semi-arid climate and ephemeral stream flow regime have often low influence on sediment input to its coastal waters. This historical trend persists when coastal watersheds remain undisturbed, thus providing optimum conditions for the development of healthy coral reefs (Ramos-Scharrón et al., 2012). However, an increasing trend of unsustainable development, alteration of coastal watersheds, and bare soil exposure have increased sediment delivery to 
Culebra's coastal waters during heavy rainfall events and have caused a live coral cover decline (Ramos-Scharrón et al., 2012; Hernández-Delgado et al., 2014a). The susceptibility of soil erosion by storm water runoff is aggravated by a general lack of appropriate sediment erosion control practices, the extension of dirt roads network, and the deforestation of coastal buffer zones (Ramos-Scharrón and MacDonald, 2007; Hernández-Delgado et al., 2011, 2012, 2014a; Ramos-Scharrón et al., 2012; Sturm et al., 2014). At the same time, an increase in popularity of Culebra Island beaches has intensified the use of coastal areas by increasing vehicle traffic (Hernández-Delgado et al., 2014a). These combinations of emergent land use activities have resulted in coastal gully erosion, and sediment influx increase to coral reef study sites. In the last decade, sedimentation threats to coral reef underwater and placed on a dark environment and laboratory room temperature until analyzed within $72 \mathrm{~h}$.

In the laboratory, supernatant water was siphoned until water reached $2.4 \mathrm{~cm}$ on top of sediment deposited on the sediment trap. The remaining water and sediment sample was decanted to centrifuge tubes and processed in a Centrifuge 5810 Eppendorf for $5 \mathrm{~min}$ at 3,500 rpm. Supernatant water was decanted and sediments were placed in an evaporating dish to oven dry at $60^{\circ} \mathrm{C}$ for $24 \mathrm{~h}$, or until a constant weight was achieved (Edmunds and Gray, 2014). Total dry sediment weight was recorded on an electronic analytical balance. Sedimentation rate was calculated with the diameter of the sediment trap $(r)$ and days of trap deployment following Equation (1) (Rogers et al., 1994; Storlazzi et al., 2009; Edmunds and Gray, 2014).

$$
\text { sediment accumulation rate }=\frac{\text { sediment weight }(\mathrm{mg})}{\text { Number of days sediment trap at site } \times \pi \times r^{2}(\mathrm{~cm})}
$$

ecosystems have become a local management priority to conserve Culebra's valuable coral reefs (DNER, 2013).

The goal of this study was to assess sedimentation spatiotemporal patterns and dynamics across near-shore coral reef ecosystems as a function of contrasting land use, precipitation, and oceanographic hydrodynamics. Therefore, this study aimed to (i) assess spatial and temporal sediment accumulation rates, grain size, and composition, and (ii) assess spatial and temporal variability of sedimentation dynamics as a response to meteorological and oceanographic conditions in two near-shore coral reefs in small semi-arid island of Culebra.

\section{MATERIALS AND METHODS \\ Data Acquisition, Field Sampling, and Laboratory Analyses}

Culebra Island is a mid-shelf semi-arid island located $27 \mathrm{~km}$ off the eastern coast of Puerto Rico, in the northeastern Caribbean Sea. The study was conducted from February 2014 to April 2015 across two leeward coral reef locations: Bahía Tamarindo (BTA, $18^{\circ} 18^{\prime} \mathrm{N}, 65^{\circ} 19^{\prime} \mathrm{W}$ ) and Punta Soldado (PSO, $18^{\circ} 16^{\prime} \mathrm{N}, 65^{\circ} 17^{\prime}$ W; Figure 1).

Sediment samples were collected on PVC cylinder sediment traps with a height of $22 \mathrm{~cm}$ and circular aperture of $5.5 \mathrm{~cm}$ (4:1 height to diameter ratio), following Storlazzi et al. (2009) recommendation for aspect ratio. Sediment traps were deployed $40 \mathrm{~cm}$ above sea floor at both sites. The study consisted of 12 sampling periods with an average of 30 days. Sediments deposited on each trap were used to estimate vertical flux of sediment particles as a proxy of sedimentation rate (Smith et al., 2008; Storlazzi et al., 2011). Sampling stations consisted of three replicate traps located across two distance zones from the coastline. Zone A ( $<60 \mathrm{~m}$ from shore) had a depth range from 1.5 to $3 \mathrm{~m}$, and zone $\mathrm{B}$ (>60 $\mathrm{m}$ from shore) had a depth range from 3 to $6 \mathrm{~m}$. In BTA there were three sampling stations along zone $\mathrm{A}$ and two along zone $\mathrm{B}$, with a total of 15 sediment traps. In PSO there were a total of two sampling stations along zone A and B, with a total of 12 sediment traps. Traps were capped
Consolidated dry sediment was disaggregated in a ceramic mortar. Sediment texture was analyzed through dry sieving techniques to classify particles into grain size, silt-clay $(<63$ $\mu \mathrm{m}, 4 \Phi)$, and sand (>63 $\mu \mathrm{m}, 4 \Phi)$ fractions (Folk, 1974). Silt and clay particles are recognized to originate from terrigenous sources and calcareous sediments are derived from biological sources and processes in the marine environment (Torres and Morelock, 2002; Hernández-Cruz et al., 2009; Edmunds and Gray, 2014).

The organic matter, carbonate, and terrigenous composition of sediment samples were determined stoichiometrically, with a sequential weight loss following the Loss on Ignition (LOI) method (Heiri et al., 2001; Edmunds and Gray, 2014). Subsamples (at least $500 \mathrm{mg}$ ) of sand and silt-clay portions were placed on pre-weighed crucibles and were burnt on muffle furnace for $3 \mathrm{~h}$ at $550^{\circ} \mathrm{C}$ to assess organic carbon composition. Sediment weight loss was recorded and samples were exposed for 3 additional hours at $950^{\circ} \mathrm{C}$ to assess the carbonate fraction (Bengtsson and Enell, 1986; Heiri et al., 2001; Edmunds and Gray, 2014). Terrigenous sediment proportion (\%) was calculated by subtracting the organic and carbonate proportion from sample weight prior to LOI. Afterwards, this proportion was multiplied by the sediment accumulation rate to get the terrigenous sediment accumulation rate (Gray, 2012).

Rainfall intensities were documented with a HOBO RG3 (Onset Computers, Co.) rain gauge located at a coastal watershed adjacent to coral reef study sites. Total monthly rainfall data were acquired from Culebra Hill station of National Weather Service online database (https://www.ncdc.noaa.gov/cdo-web/datatools/ findstation), while historical rainfall data were acquired from a local resident rain gauge (W. Kunke, unpub. data). Simple daily intensity index was calculated as the ratio of total precipitation to number of wet days ( $\mathrm{mm} /$ day) according to Zhang et al. (2011) to assess the relationship with sedimentation dynamics in the coral reef. Other abiotic variables related to oceanographic hydrodynamics, such as wave height, dominant wave period, wind speed, and wind gusts were acquired from the Caribbean Integrated Coastal Ocean Observing System (CariCOOS) online 


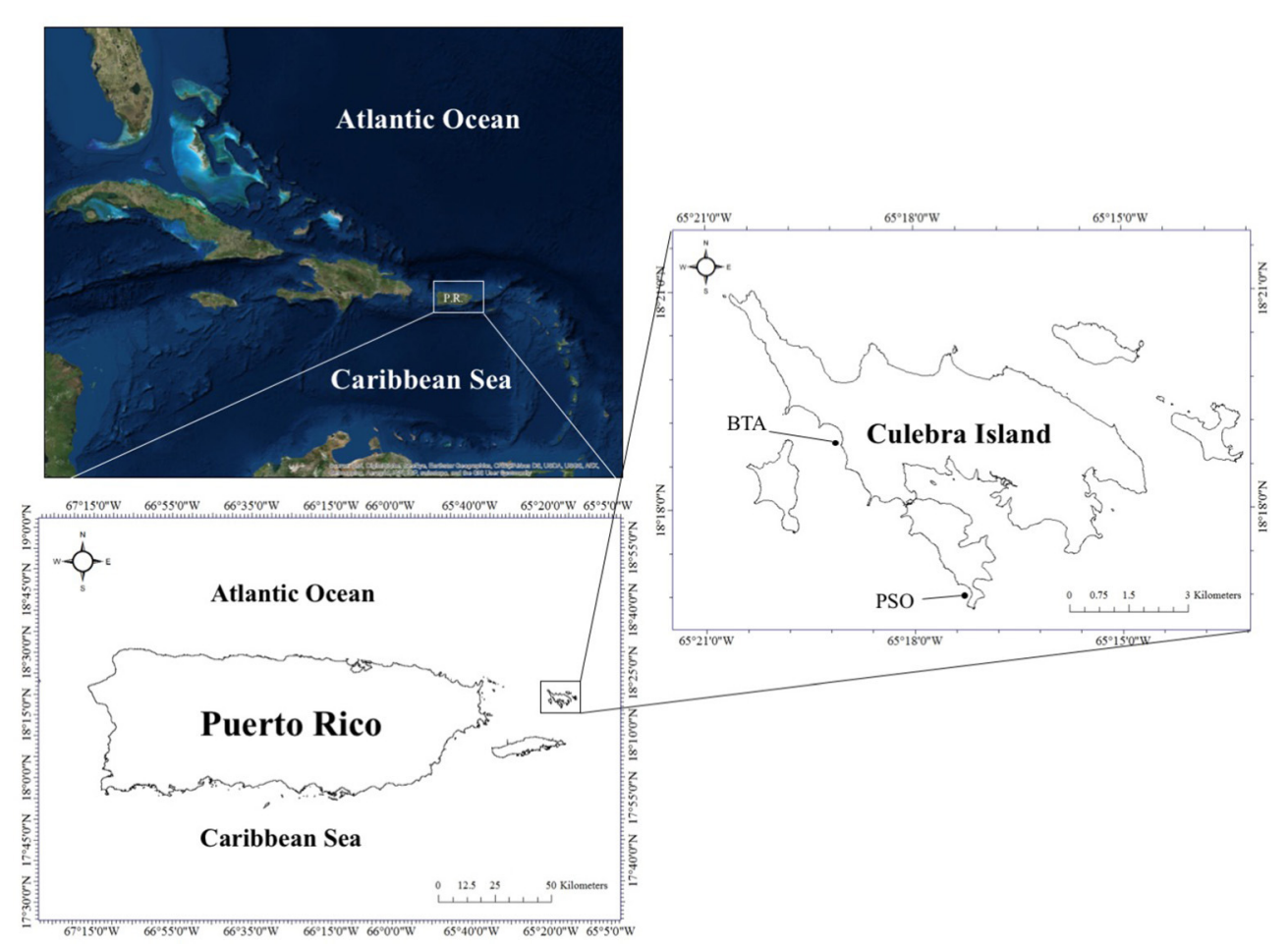

FIGURE 1 | Study site at Culebra Island, Puerto Rico. BTA, Bahia Tamarindo; PSO, Punta Soldado.

database (http://www.caricoos.org/data-download, buoy NDBC 41056 located at Vieques sound.

\section{Statistical Analyses}

Sediment data were tested using four-way non-parametric permutational analysis of variance (PERMANOVA) and pairwise comparison for the fixed factors of seasons, time, site and distance from shore (Anderson et al., 2008). Significant relationship was identified by factors that had $P<0.0500$. Ranks ordering of dissimilarities were acquired through Euclidean distance resemblance measure (Clarke et al., 2014). Non-metric multi-dimensional scaling (nMDS) and principal coordinate ordination analysis (PCO) were afterwards tested to acquire a display of the spatial and temporal patterns of variation (Anderson et al., 2008). The nMDS and PCO ordination analysis provided a simple graphical representation in low dimensional space (two or three dimensions), where points represented assessed sediment characteristics, and the distance between points preserved the original rank order of dissimilarities (Anderson et al., 2008; Clarke et al., 2014). Therefore, the nMDS and PCO ordination techniques provide a straightforward interpretation of multivariate data showing how much sediment samples relate to each other, or how much relationship exists between the factors being analyzed (Chariton et al., 2016). The centroids from multivariate sediment data and the Euclidean distance from each pair of centroids were used to create the PCO ordinations plot (Gower, 1966; Anderson et al., 2008). Vectors were superimposed to assess how sediment and environmental factors explained spatio-temporal variation. BEST BIO-ENV and RELATE (Spearman rank) correlations were used to determine the best environmental variables that explained observed sedimentation patterns (Clarke and Ainsworth, 1993). Analyses were conducted in PRIMER v7 and PERMANOVA v1.16 statistical programs (Plymouth Marine Laboratory, UK). Linear regression analysis was conducted on SigmaPlot 11.0 (Systat software Inc.) to determine the relationship between sediment and environmental variables and was also used for graphical representation of data. Sediment variables and environmental data, including weather and oceanographic hydrodynamics data (i.e., precipitation, wave height, dominant wave period, etc.), were $\log _{10}$-transformed prior to analyses to meet assumptions of normality and homogeneity of variances (Smith et al., 2008; Gotelli and Ellison, 2013). All multivariate tests were based in 10,000 permutations (Anderson, 2001; Hernández-Delgado et al., 2014b).

\section{RESULTS}

\section{Sedimentation Rate}

Sedimentation rate patterns were significantly different among time periods (PERMANOVA, Pseudo $F=57.21, p=0.0001$ ), and distance zone from shore (Pseudo $F=16.54$, $p=0.0040$; Table 1). There was also a significant difference among time by distance (Pseudo $F=5.94, p=0.0010$ ), and site by distance interactions (Pseudo $F=11.18, p=0.0100$ ). Nevertheless, sedimentation rate patterns did not show a significant difference 
TABLE 1 | Results of a permutational analysis of variance (PERMANOVA) sedimentation rate and terrigenous rate.

\begin{tabular}{|c|c|c|c|c|c|c|}
\hline \multirow[t]{2}{*}{ Factors } & \multicolumn{3}{|c|}{ Sedimentation rate } & \multicolumn{3}{|c|}{ Terrigenous rate } \\
\hline & df & Pseudo $F$ & $P$ (perm) & df & Pseudo F & $\boldsymbol{P}$ (perm) \\
\hline Season (Se) & 3 & 1.46 & 0.2800 & 3 & 3.80 & 0.0700 \\
\hline Time (Ti) & 8 & 57.21 & 0.0001 & 7 & 35.12 & 0.0001 \\
\hline Site (Si) & 1 & 2.62 & 0.1500 & 1 & 7.38 & 0.0300 \\
\hline Distance (Di) & 1 & 16.54 & 0.0040 & 1 & 12.07 & 0.0100 \\
\hline $\mathrm{Se} \times \mathrm{Si}$ & 3 & 0.88 & 0.4900 & 3 & 4.14 & 0.0600 \\
\hline $\mathrm{Se} \times \mathrm{Di}$ & 3 & 2.12 & 0.2000 & 3 & 3.01 & 0.0900 \\
\hline $\mathrm{Ti} \times \mathrm{Si}$ & 8 & 39.54 & 0.0001 & 7 & 18.52 & 0.0001 \\
\hline $\mathrm{Si} \times \mathrm{Di}$ & 1 & 11.18 & 0.0100 & 1 & 21.18 & 0.0030 \\
\hline $\mathrm{Se} \times \mathrm{Si} \times \mathrm{Di}$ & 3 & 0.25 & 0.8200 & 3 & 2.51 & 0.1400 \\
\hline $\mathrm{Ti} \times \mathrm{Si} \times \mathrm{Di}$ & 8 & 5.70 & 0.0010 & 7 & 3.50 & 0.0300 \\
\hline
\end{tabular}

by seasons or sites. Sediment accumulation rate was consistently higher at BTA with $2.42 \pm 0.42 \mathrm{mg} \mathrm{cm}^{-2} \mathrm{~d}^{-1}$ (mean \pm standard error) for the whole study period, and $0.47 \pm 0.05 \mathrm{mg} \mathrm{cm}^{-2}$ $\mathrm{d}^{-1}$ at PSO. In BTA significant sediment pulses were recorded from December 2014 to February 2015, and from October to November 2014, corresponding to extreme rainfall and runoff events during winter and autumn seasons respectively (Figure 2A). Total rainfall during these two periods was 171.20 and $182.37 \mathrm{~mm}$, respectively. Mean sedimentation rate in BTA during the winter season was $6.84 \pm 2.14 \mathrm{mg} \mathrm{cm}^{-2} \mathrm{~d}^{-1}$.

At BTA the highest sediment accumulation occurred at distance zone A $(<60 \mathrm{~m})$ and for these sampling periods mean total sediment accumulation was $6.80 \mathrm{mg} \mathrm{cm}^{-2} \mathrm{~d}^{-1}$ (OctNov) and $21.04 \mathrm{mg} \mathrm{cm}^{-2} \mathrm{~d}^{-1}$ (Dec-Feb 2015; Figure 2B). The highest total rainfall was recorded from October to November, with values up to $171.20 \mathrm{~mm}$. Rainfall reached $182.37 \mathrm{~mm}$ from December 2014 to February 2015. Likewise, for these sampling periods with greatest sediment accumulation rate a high frequency of intense wave height $(>1 \mathrm{~m})$ was also experienced. It can be suggested that coral reefs located at BTA had a higher exposure to sedimentation stress associated with runoff from intense rainfall events. Mean sedimentation rate at BTA during the winter season was $6.84 \pm 2.14 \mathrm{mg} \mathrm{cm}^{-2} \mathrm{~d}^{-1}$. The highest sediment pulse (Dec-Feb) had a percent increase of $1,259 \%$ from the period with lowest sedimentation rate, recorded from June to July 2014. The second in magnitude (Oct-Nov) had a percent increase of $386 \%$. After a rainfall peak registered in April 2014 an extreme drought event persisted across the wider Caribbean region that lasted until August 2014 (Figure 3), and was related with the period with lowest sediment accumulation rate for both sites (Figure 2A). Sediment accumulation at PSO had an overall lower mean rate and a single sedimentation pulse event was recorded from July to August, with a mean rate of 1.52 $\pm 0.05 \mathrm{mg} \mathrm{cm}^{-2} \mathrm{~d}^{-1}$. It had a percent increase of $52 \%$ from the period with lowest sedimentation rate recorded from February to March 2014. Moreover, sediment accumulation at PSO was non-significant by distance zones (Figure 2C).

Terrigenous sediment accumulation rate showed a significant difference among time, site and distance zones (Table 1).
However, difference among seasons was marginally significant (Pseudo $F=3.80, p=0.0700$ ). Terrigenous accumulation rate had a similar pattern as sedimentation rate, yet they differed since terrigenous accumulation rate shows the portion of sediment derived from land. At BTA terrigenous sediment accumulation had a total mean of $1.25 \pm 0.2 \mathrm{mg} \mathrm{cm}^{-2} \mathrm{~d}^{-1}$, which was significantly higher than at PSO. In PSO the mean terrigenous sediment accumulation was of $0.16 \pm 0.2 \mathrm{mg} \mathrm{cm}^{-2} \mathrm{~d}^{-1}$. The highest terrigenous accumulation rate in BTA was documented from December to February 2015, with a mean of $6.35 \mathrm{mg}$ $\mathrm{cm}^{-2} \mathrm{~d}^{-1}$ (Figure 2D). There was a great difference from the terrigenous sediment accumulated at BTA between the distance zones (Pair-wise $t=3.94, p=0.0050$ ). Closer to shore, zone A, the terrigenous sediment reached accumulation rate of 9.86 $\mathrm{mg} \mathrm{cm} \mathrm{cm}^{-2} \mathrm{~d}^{-1}$ from December to February 2015 and 3.23 from October to November 2014. Total terrigenous sediment accumulation rate had a mean of $1.25 \mathrm{mg} \mathrm{cm}^{-2} \mathrm{~d}^{-1}$, while zone $\mathrm{B}$ had a mean of $0.39 \mathrm{mg} \mathrm{cm}^{-2} \mathrm{~d}^{-1}$. At PSO, the mean terrigenous sediment accumulation rate also had similar patterns as sedimentation rate. The sampling period with highest accumulation was from July to August, and it was associated with period of intense rainfall after long drought period.

\section{Sediment Dynamics}

Sediment dynamics showed a significant difference between sites (Pseudo $F=9.05, p=0.0020$ ) and distance from shore (Pseudo $F=10.71, p=0.0030)$. Also, the interactions of site and distance (Pseudo $F=7.01, p=0.0060$ ), time and site (Pseudo $F=14.20$, $p=0.0001$ ), time and distance (Pseudo $F=2.35, p=0.0020$ ), time and site and distance (Pseudo $F=1.87, p=0.0200$ ) were significant. The principal coordinate analysis ordination (PCO) identified three large clusters from the overall sediment patterns by season, site, and distance zone (Figure 4). The farthest cluster was identified by similar sediment dynamics at fall and winter seasons in BTA zone A. It had a strong relationship with major variations in sedimentation rate, terrigenous rate, terrigenous content, and sand. However, sediment dynamics during winter season at zone B was explained by variation in sand grain size. Organic matter was a key factor during summer season at both distance zones, and it might be related to deposition due to lower wave energy. Sediment dynamics in PSO at both distance zones responded predominantly to variations in silt-clay grain size sediment and carbonate content. During winter season there was a critical rainfall event that produced a significant silt-clay input that reached zone B. Nevertheless, zone A had similarity to patterns explained for BTA at spring, fall and winter seasons. The proposed PCO explains $97 \%$ of the observed patterns of variation in sedimentation dynamics.

\section{Sediment Texture}

Sediment texture was significantly different among time series (Pseudo $F=5.55, p=0.0010$ ), sites (Pseudo $F=31.26, p$ $=0.0010$ ), and for the interactions time by site (Pseudo $F=$ $8.70, p=0.0001$ ), and site by distance (Pseudo $F=5.52, p=$ 0.0300; Table 2). Sediment grain size categories, sand and siltclay showed similar spatio-temporal patterns, with significant differences among time series and sites. However, there was 
A
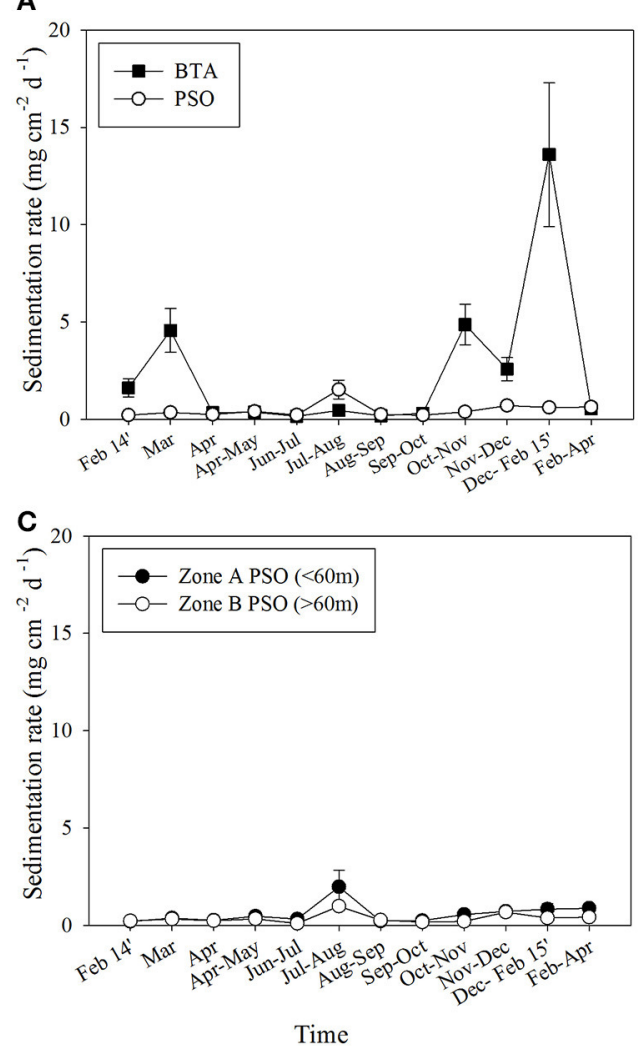

B

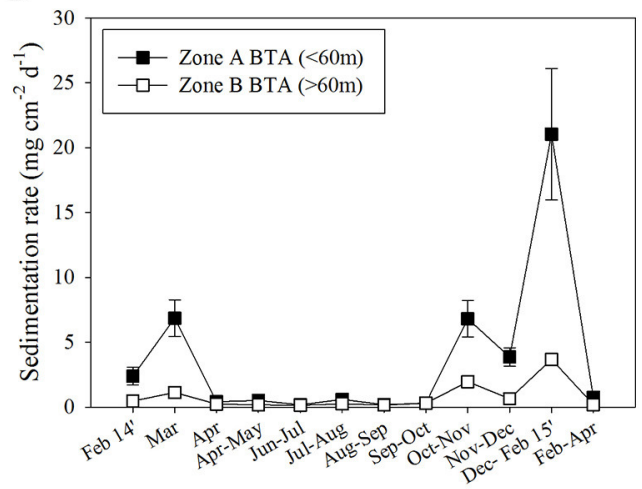

D

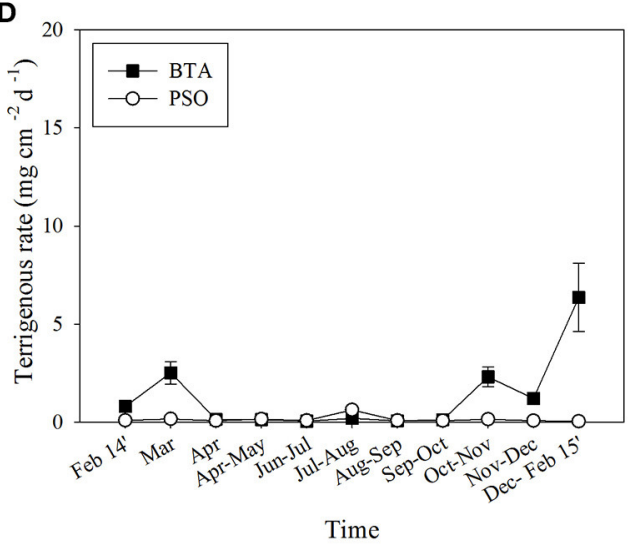

FIGURE 2 | Sedimentation rate ( \pm S.E.) for both sites (A), sedimentation rate at BTA by distance zones (B), sedimentation rate at PSO by distance zones (C), terrigenous rate for both sites (D).

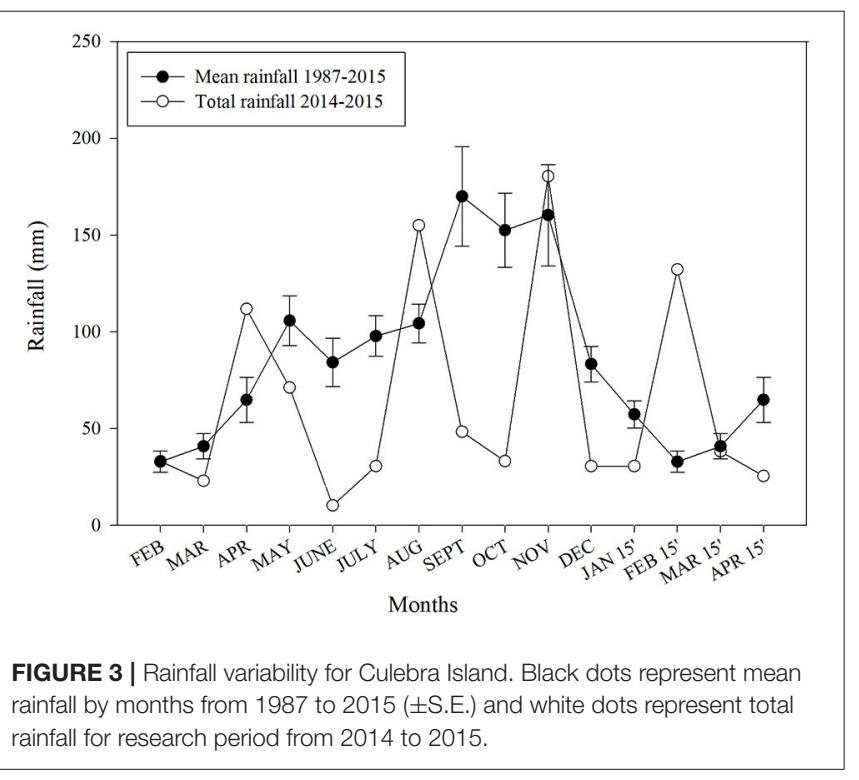

no significant difference among seasons or between distance zones. Sediments that accumulated along BTA reef had a major influence of sand particles. The accumulation of the sand, coarser-grained sediments in overall had a mean proportion of $65 \%$, with the highest proportion being recorded at both distances zones from December 2014 to February 2015, with a mean of $83 \%$ (Figure 5A). This period corresponded to winter season (Figure 5B). Similarly, for this sampling period a mean wave height at BTA of $1.16 \mathrm{~m}$ was documented, with a dominant wave period or the period with maximum wave energy of $8.45 \mathrm{~s}$, and wind speed ranging from 2.45 to $8.30 \mathrm{~m} / \mathrm{s}$ (Figures 6A-C). It also showed that $45 \%$ of days wave height overpassed $1 \mathrm{~m}$ and $13 \%$ of days waves were higher than $1.5 \mathrm{~m}$. At BTA sand accumulation at sampling stations ranged from $9 \%$ to $96 \%$ in zone $\mathrm{A}$ and from $7 \%$ to $90 \%$ in zone B. In contrast, silt-clay accumulation had a mean proportion of $30 \%$. The highest accumulation of fine sediments proportion was recorded during sampling period April to May and July to August, with a mean of $40 \%$ for both time intervals. These time periods corresponded to spring and summer seasons, respectively, which were characterized by calmer oceanographic conditions. During these seasons, multiple meteorological systems were also experienced (i.e., cold fronts and tropical storms) that produced extreme rainfall at the northeastern Caribbean region.

PSO showed contrasting sediment accumulation patterns, since in overall it had slightly higher proportions of silt-clay grain size sediments (Figure $\mathbf{5 C}$ ). The fine-grained sediment had a mean proportion percent of $50 \%$ and the highest proportion was recorded from December to February 2015, 

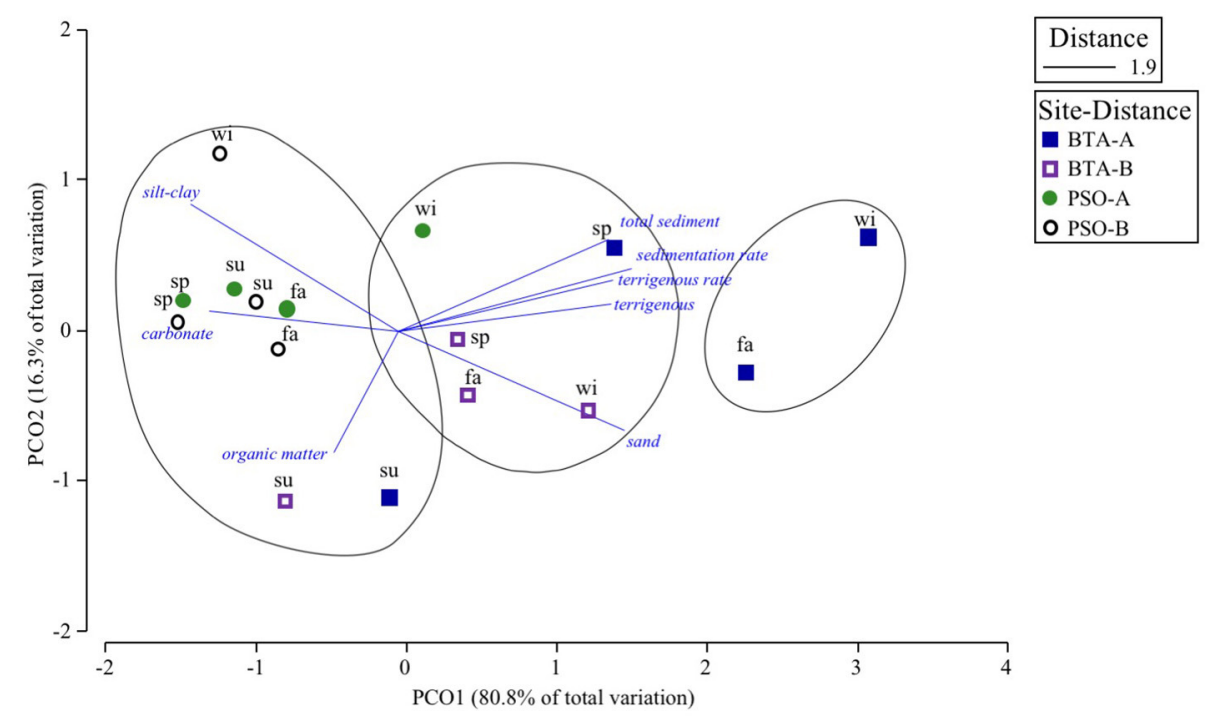

FIGURE 4 | Principal coordinate ordination (PCO) analysis of centroids of sedimentation components by seasons, sites and distance zone from shore based on Euclidean assemblage data. Squares represent BTA and circles PSO. Clusters based on a Euclidean distance cutoff level of 1.9. This model explained 97.1\% of the observed spatio-temporal variation in sedimentation patterns. Seasons are represented as sp, spring; su, summer; fa, fall; wi, winter.

TABLE 2 | Results of a permutational analysis of variance (PERMANOVA) of sediment texture, sand, and silt-clay grain size sediments.

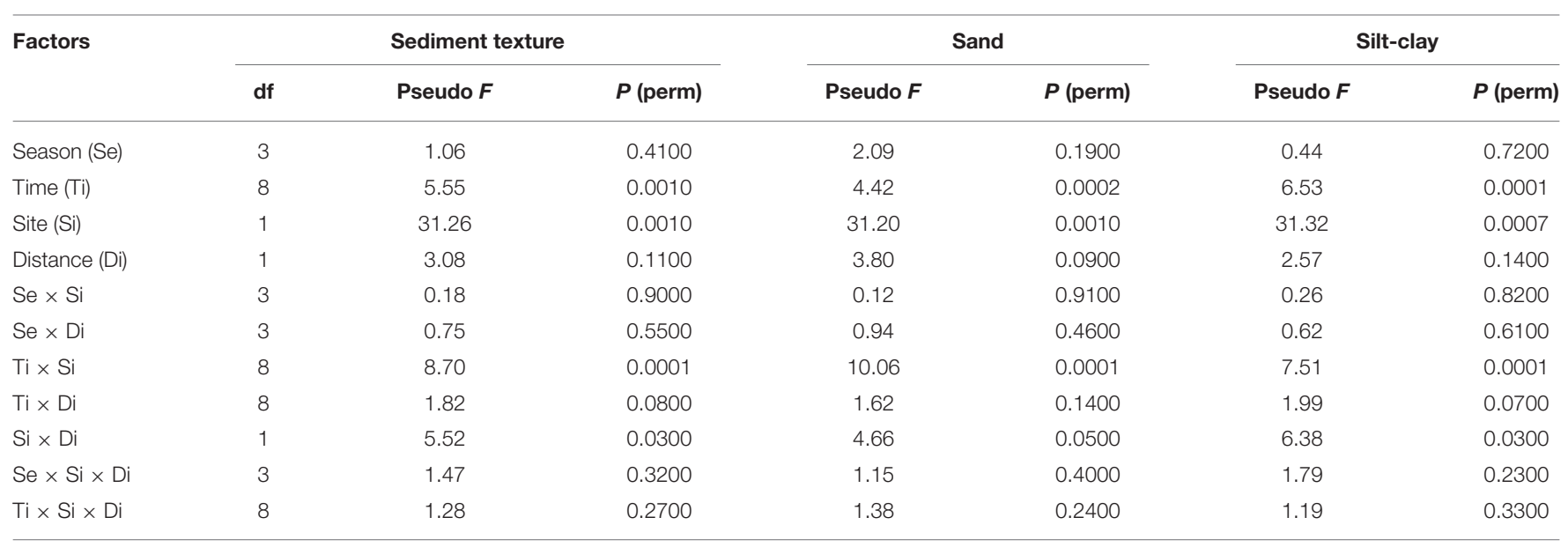

and from April to May, with a mean proportion of 57\% for both sampling periods following rainfall pulse events. A significant difference was observed between zones, as a consequence that zone $B$ received a higher portion of siltclay sediments. Silt-clay particles that accumulated along the reef ranged from 18 to $66 \%$ in zone A, and from 3 to $94 \%$ in zone $\mathrm{B}$, showing drastic variations throughout the study. Subsequent to a massive deforestation event that occurred on April 2014 along the steep coastal watershed of PSO the silt-clay sediment accumulation increased and it was a major contribution to sedimentation fluxes across the coral reef during intense rainfall events. However, sand particles accumulation in PSO had the highest distribution from November to December, with a mean of $54 \%$. During this sampling period sand accumulation proportion in zone A reached a mean of $62 \%$ and a maximum of $85 \%$. However, there was no significant difference for sediment distribution in PSO across seasons (Figure 5D). Documented mean wave height for November to December sampling period was of $1.22 \mathrm{~m}$, dominant wave period of $8.78 \mathrm{~s}$, with $61 \%$ of days overpassing a wave height of $1 \mathrm{~m}$, and $19 \%$ of days the waves were higher than $1.5 \mathrm{~m}$ (Figures 6A,B).

nMDS analysis showed three distinct clusters of sites and distance zone by time, based on the proportion of sand grain size category distribution (Figure 7A). The farthest cluster included four events of major sand distribution, predominantly across BTA zone A, suggesting strong recurrent sediment resuspension and bedload transport episodes. These events were associated to a combination of cold fronts and tropical storms that produced extreme rainfall events with significant runoff, surface 


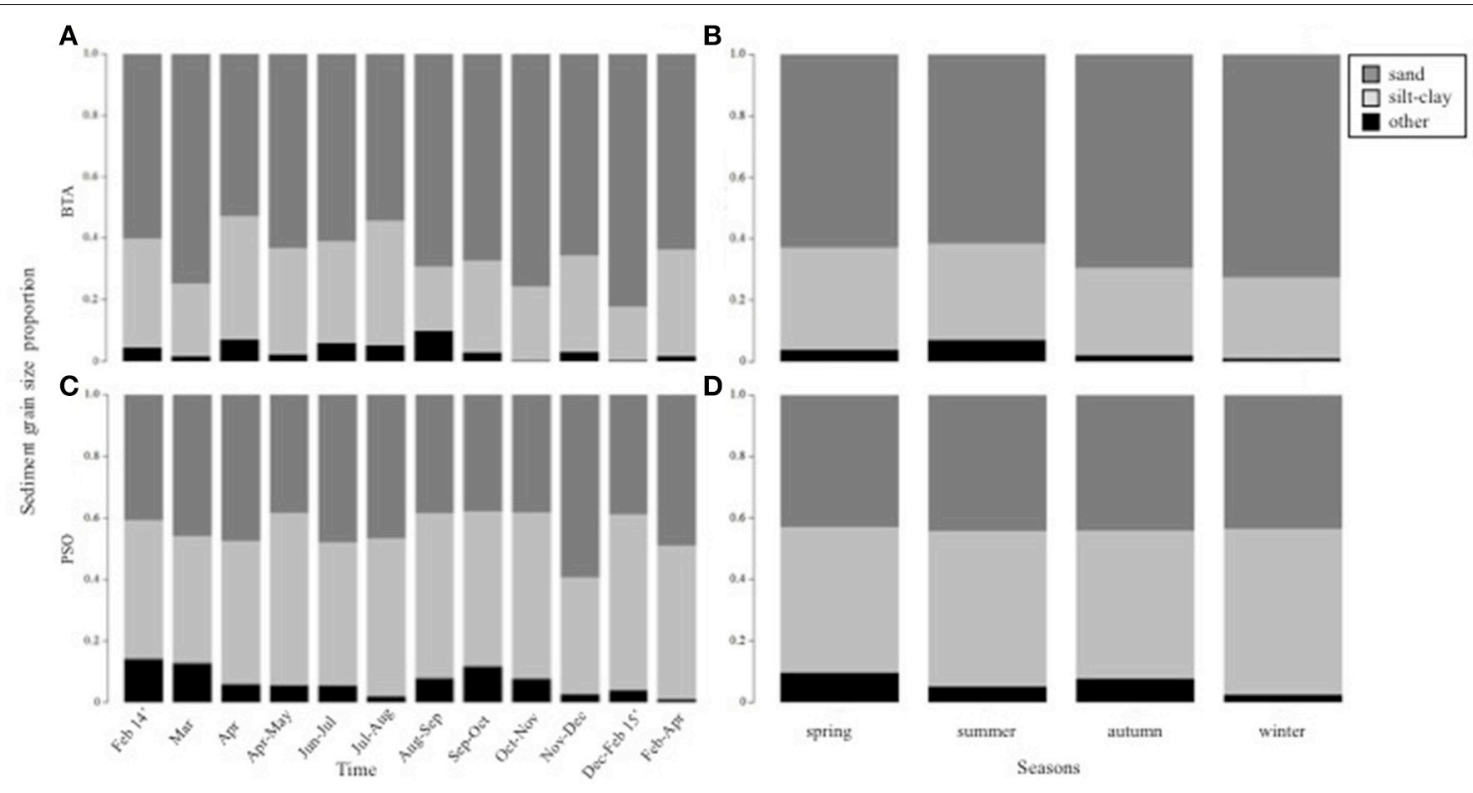

FIGURE 5 | Patterns of variation in sediment grain size proportion by time and season at BTA (A,B) and PSO (C,D). Dark gray stacked bar: sand, light gray: silt-clay, and black: other.

erosion and swells. Therefore, it can be suggested that sand is transported predominantly through inner coastal areas during periods of active ocean conditions, either by waves or windinduced turbulence. Besides these extreme events, sand showed a decreasing gradient of effects with similar distribution patterns across most of the remaining events at BTA through zones A and $\mathrm{B}$, evidencing a significant difference between distance zones (Pair-wise, $t=3.09, p=0.0100$ ). The remaining cluster included the majority of events or sampling periods of PSO, with no significant difference between distance zones.

The second nMDS plot shows three distinct clusters of sites and distance zone by time, based on the proportion of siltclay grain size category distribution (Figure 7B). It shows a gradient of events that distinguished silt-clay distribution from BTA and PSO. In PSO the majority of the events reached a similar silt-clay distribution between distance zones. However, during two events, there were major silt-clay sediment input and distribution that significantly accumulated or deposited across distance zone B. These events were associated with the tropical trough and cold fronts that produced extreme rainfall, and combined with surface erosion, runoff, and sediment delivery to coastal waters. These events highlighted the ability of fine sediments to remain suspended in the water column long distances and settle far from shore $(>60 \mathrm{~m})$ on coastal benthic communities during calmer oceanographic conditions. The remaining two clusters indicated significant differences between distance zone A and B at BTA (Pair-wise, $t=2.85, p=0.0200)$. Both nMDS plots had a very low stress value $(0.01)$, suggesting that the plots are an accurate spatial representation of the sediment grain size differences of distribution and accumulation between time, sites, and distance zones.

\section{Sediment Composition}

Sediment composition analysis showed a statistically significant difference among time series (Pseudo $F=13.58, p=0.0001$ ), between distance zones (Pseudo $F=4.15, p=0.0400$ ), and the interaction time series and sites (Pseudo $F=11.45, p=$ 0.0001; Table 3). The largest variation in sediment composition was caused by calcium carbonate $\left(\mathrm{CaCO}_{3}\right)$ and terrigenous material, as a consequence of the low content of organic matter contributing to $<10 \%$ of sediment assessed for both sites. The average $\mathrm{CaCO}_{3}$ content across BTA reef was $45 \%$ (Figure 8A), with the highest $\mathrm{CaCO}_{3}$ content recorded from April to May, and from June to July. The season with the highest $\mathrm{CaCO}_{3}$ proportion was summer, with a mean of $48 \%$ (Figure $8 B$ ); however there was no significant difference among seasons. Overall, $\mathrm{CaCO}_{3}$ content was similar between distance zones and showed no significant difference. Sediments that accumulated across the reef had mean $\mathrm{CaCO}_{3}$ content ranging from 27 to $84 \%$. There was a similar pattern for terrigenous content with a mean of $45 \%$. The highest terrigenous content was recorded at sediments that accumulated from March to April 2014, corresponding to spring season, at both distance zones. Terrigenous content that accumulated across the reef ranged from 7 to $65 \%$, representing great sediment accumulation along the study period.

Sediments that accumulated across PSO reef had a mean $\mathrm{CaCO}_{3}$ content of $50 \%$, greater than BTA. The highest $\mathrm{CaCO}_{3}$ content was identified from April to May 2014 (Figure 8C), which corresponded to calmer oceanographic conditions and increased fine-grained sediment deposition in the reef. However, there was no significant difference among seasons (Figure 8D). Meanwhile, terrigenous content in PSO had a mean percent of $40 \%$. The highest terrigenous content was identified in sediment that accumulated from February to March 2014, with a mean 

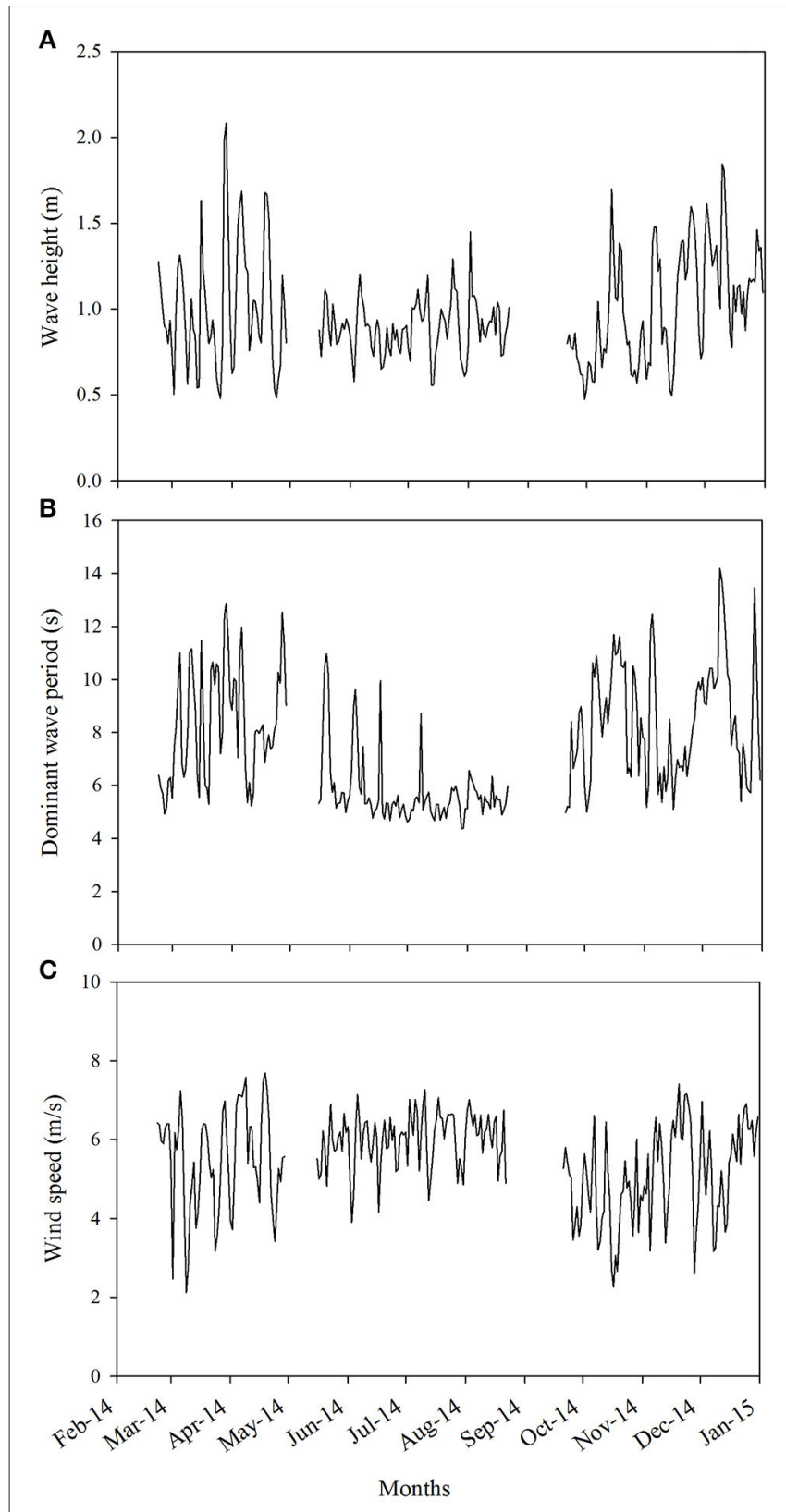

FIGURE 6 | Variations of meteorological and oceanographic environmental data through the study period. Wind speed $(\mathbf{A})$, dominant wave period $(\mathbf{B})$, and wind speed $(\mathbf{C})$. Data acquired from CARICOOS NDBC 41056 buoy.

percent of $45 \%$, but there was no significant difference between distance zones. However, the highest terrigenous accumulation occurred during fall and winter season with a mean value of $41 \%$ for both seasons. Terrigenous sediment that accumulated across the reef ranged from 32 to $43 \%$, representing consistently higher levels.

nMDS plot shows two distinct clusters based on the proportion of marine sediment terrigenous content that mostly distinguished distribution between sites (Figure 9). The plot shows a gradient of events at BTA, indicating that the proportion of terrigenous sediment accumulation experienced variations
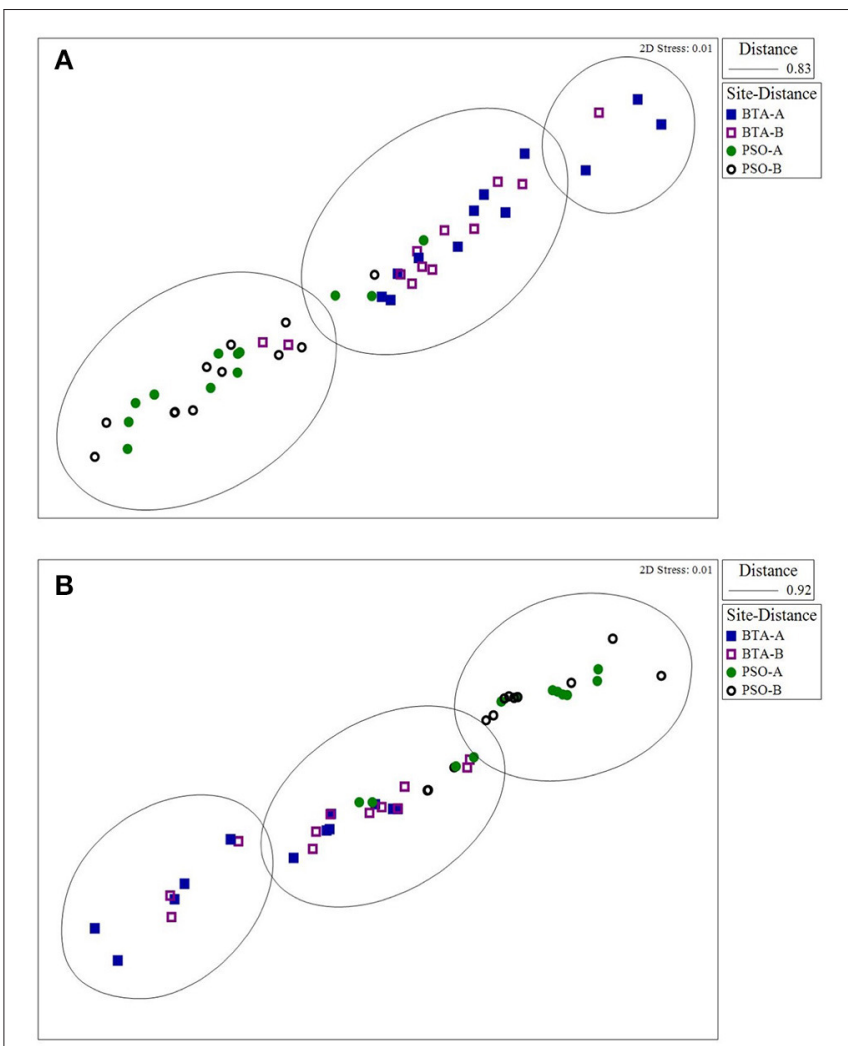

FIGURE 7 | Non-metric multidimensional scaling (nMDS) plot for sand grain size (A) and silt-clay (B) by time, site, and distance zones. Clusters are based on a Euclidean distance cutoff level of 0.83 (A) and 0.92 (B). Ordination diagram shows sediment particle grain size distribution on first two dimensions, $X$ axis (nMSD1) and $Y$ axis (nMDS2).

by seasons and across distance zones. BTA experienced higher terrigenous sediment accumulation during most of the study, except for the summer on distance zone B, while there were calmer meteorological conditions. Overall, terrigenous sediment accumulation was $5 \%$ higher in BTA than in PSO. In PSO, most of the seasons received similar terrigenous content within different distance zones. However, the plot shows that for both sites terrigenous content was higher on the distance zone closer to shore on spring, fall and winter. These seasons were associated with cold fronts and frontal boundary events that produced extreme and intense rainfall events and provoked significant soil erosion, runoff and terrigenous sediment influx to inner coral reef areas. The nMDS plots had a very low stress value (0.01), suggesting that it is an accurate spatial representation of the terrigenous sediment differences of distribution and accumulation among sites, and between distance zones by seasons.

\section{Sedimentation Patterns and Environmental Variables}

Sedimentation rate, sediment texture, and composition responded differently to variations in environmental conditions. Regression analyses indicated that sedimentation rate had a 
TABLE 3 | Permutational analysis of ANOVA (PERMANOVA) for sediment composition, organic matter, $\mathrm{CaCO}_{3}$, and terrigenous content of sediments.

\begin{tabular}{|c|c|c|c|c|c|c|c|c|c|}
\hline \multirow[t]{2}{*}{ Factors } & \multicolumn{3}{|c|}{ Sediment composition } & \multicolumn{2}{|c|}{ Organic matter } & \multicolumn{2}{|c|}{$\mathrm{CaCO}_{3}$} & \multicolumn{2}{|c|}{ Terrigenous } \\
\hline & df & Pseudo $F$ & $P$ (perm) & Pseudo F & $P$ (perm) & Pseudo $F$ & $P$ (perm) & Pseudo F & $P$ (perm) \\
\hline Season (Se) & 3 & 0.17 & 0.9100 & 0.55 & 0.6500 & 0.13 & 0.8600 & 0.31 & 0.7700 \\
\hline Time (Ti) & 7 & 13.58 & 0.0001 & 6.24 & 0.0001 & 23.00 & 0.0001 & 16.82 & 0.0001 \\
\hline Site (Si) & 1 & 3.68 & 0.0800 & 0.37 & 0.5800 & 5.70 & 0.0500 & 6.07 & 0.0500 \\
\hline Distance (Di) & 1 & 4.45 & 0.0400 & 4.30 & 0.0700 & 3.21 & 0.1000 & 5.14 & 0.0500 \\
\hline $\mathrm{Se} \times \mathrm{Si}$ & 3 & 0.81 & 0.5600 & 0.29 & 0.8200 & 0.79 & 0.5500 & 1.29 & 0.3400 \\
\hline $\mathrm{Se} \times \mathrm{Di}$ & 3 & 1.09 & 0.4100 & 1.55 & 0.2700 & 3.33 & 0.0700 & 0.70 & 0.5800 \\
\hline $\mathrm{Si} \times \mathrm{Di}$ & 1 & 1.60 & 0.2500 & 8.06 & 0.0200 & 0.66 & 0.4900 & 1.95 & 0.1900 \\
\hline $\mathrm{Ti} \times \mathrm{Si}$ & 7 & 11.45 & 0.0001 & 8.59 & 0.0001 & 18.69 & 0.0001 & 9.27 & 0.0001 \\
\hline $\mathrm{Ti} \times \mathrm{Di}$ & 7 & 1.92 & 0.0700 & 1.44 & 0.1800 & 1.30 & 0.2900 & 2.53 & 0.0300 \\
\hline $\mathrm{Se} \times \mathrm{Si} \times \mathrm{Di}$ & 3 & 1.03 & 0.4400 & 1.03 & 0.4400 & 0.64 & 0.6100 & 0.37 & 0.7800 \\
\hline $\mathrm{Ti} \times \mathrm{Si} \times \mathrm{Di}$ & 7 & 1.29 & 0.2900 & 0.89 & 0.5200 & 1.31 & 0.2800 & 1.50 & 0.2000 \\
\hline
\end{tabular}

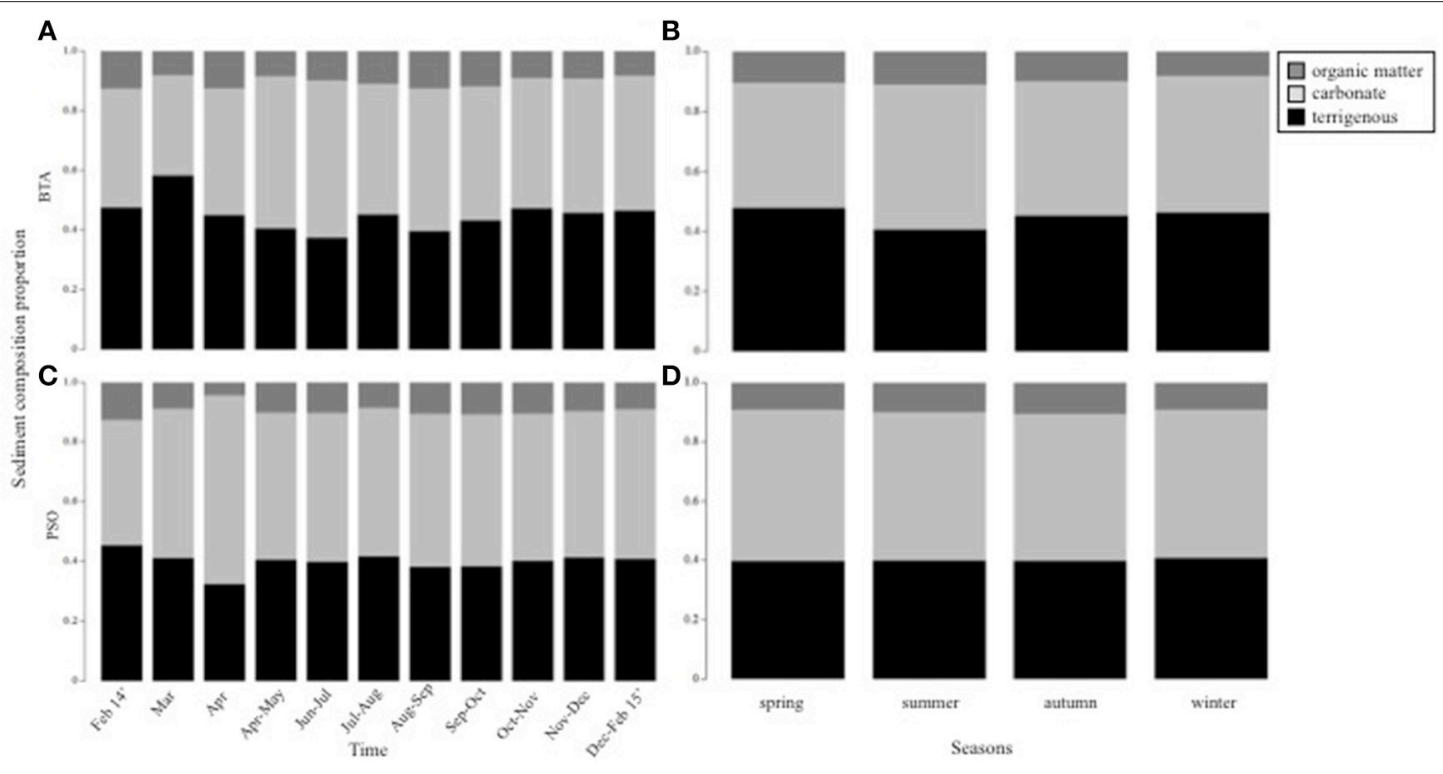

FIGURE 8 | Patterns of variation in sediment composition proportion by time (A) and seasons (B) at BTA, and PSO (C,D). Dark gray stacked bar: percent organic matter, light gray: percent $\mathrm{CaCO}_{3}$, and black: percent terrigenous.

positive marginal linear relationship with wave height in BTA $\left(r^{2}=0.33, p=0.0511\right)$, and a significant relationship with total precipitation in PSO $\left(r^{2}=0.41, p=0.0240\right.$; Figure 10). At BTA, sedimentation rate also showed a nearly marginal relationship with total precipitation $\left(r^{2}=0.25, p=0.0986\right)$ and a positive linear relationship with dominant wave period $\left(r^{2}=0.45\right.$, $p=0.0167$ ), defined as the period with maximum wave energy. The non-parametric correlation BEST BIO-ENV (Spearman rank) analysis demonstrated that terrigenous sedimentation rate had a strong correlation with total precipitation and with dominant wave period $(\mathrm{Rho}=0.36)$ by time series. Furthermore, a positive linear relationship between terrigenous rate and total precipitation $\left(r^{2}=0.40, p=0.0379\right.$ ) was documented at PSO.

There was a significant correlation between sediment texture with total precipitation, wave height, and dominant wave period
(Rho $=0.20)$ by time series. Specifically, sand $(>63 \mu \mathrm{m})$ showed a positive relationship with wave height $\left(r^{2}=0.42, p=0.0227\right)$. These patterns highlight the role of strong waves and swells produced by storms and frontal systems on the resuspension or distribution of coarser sediments along the reef (Figures 6A,C). However, silt-clay $(<63 \mu \mathrm{m})$ particle distribution along nearshore coral reefs was mostly associated to periods with higher total rainfall and rainfall intensity (Figure 11).

Sediment composition also correlated with multiple environmental variables, including total precipitation, dominant wave period, simple daily rainfall intensity index $(>1 \mathrm{~mm} /$ day), and sea surface temperature (SST; BEST BIOENV, Rho = 0.48 ) by time series. At BTA terrigenous content had a strong relationship with dominant wave period $\left(r^{2}=0.41, p=\right.$ $0.0352)$. Simple daily rainfall intensity index showed a significant 
correlation with the accumulated $\mathrm{CaCO}_{3}$ component (Rho $=0.308, p=0.0300$ ), and the relationship was marginally significant with terrigenous content $(\mathrm{Rho}=0.23, p=0.0900)$. SST showed a strong significant relationship with organic matter content $(\mathrm{Rho}=0.36, p=0.0060)$. Variations in SST might have an indirect effect on the amount of $\mathrm{CaCO}_{3}$ available on the coastal marine environment for its distribution along the reef.

\section{DISCUSSION}

There was a significant spatial and temporal variation of sedimentation dynamics along near-shore coral reef study sites of Culebra Island. Sedimentation patterns showed significant variation among sampling periods, but not among seasons. These patterns were influenced by local climate variability, characterized by rainfall peaks that differed from historic

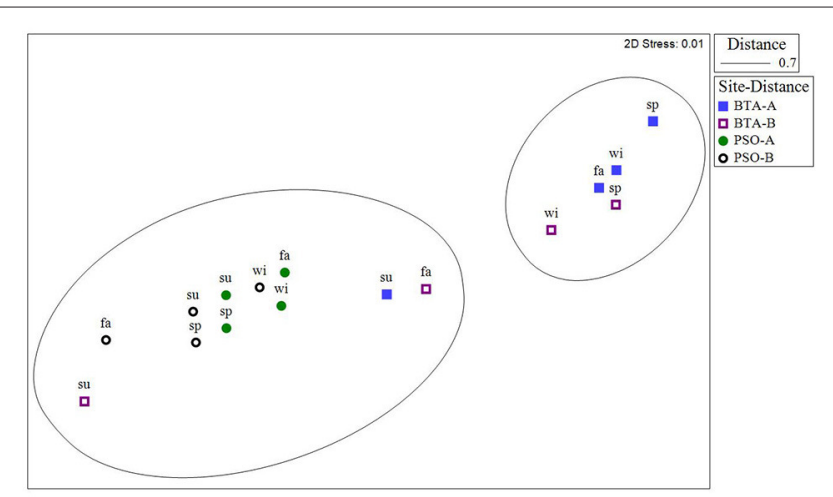

FIGURE 9 | Non-metric multidimensional scaling (nMDS) plot for terrigenous content by time, sites and distance zone from shore. Clusters based on a Euclidean distance cutoff level of 0.70 . Ordination diagram shows terrigenous content on first two dimensions, $X$ axis (nMSD1) and $Y$ axis (nMDS2). Seasons are represented as sp, spring; su, summer; fa, fall; wi, winter. rainy seasons (Figure 3). Rainfall anomalies (Appendix 1 in Supplementary Material) altered streamflow regimes on this semi-arid island, affecting terrestrial sediment influx, and sediment distribution along coastal waters. At near-shore reef spatial scales $(120 \mathrm{~m}$ from shore or less), results from this study reject the null hypothesis that contrasting land use, precipitation patterns, and oceanographic hydrodynamics do not have a significant spatial and temporal impact sedimentation rate, sediment texture, and sediment composition. Our results suggest that the reef zones closer to shore $(<60 \mathrm{~m})$ were more exposed to sedimentation stress during strong and intense rainfall events. Furthermore, increased intensity of oceanographic conditions (i.e., wind speed, wave height, and dominant wave period) triggered high variation in coastal sedimentation dynamics within our study sites. Shallow inner coral reef zones were more vulnerable to changing sediment

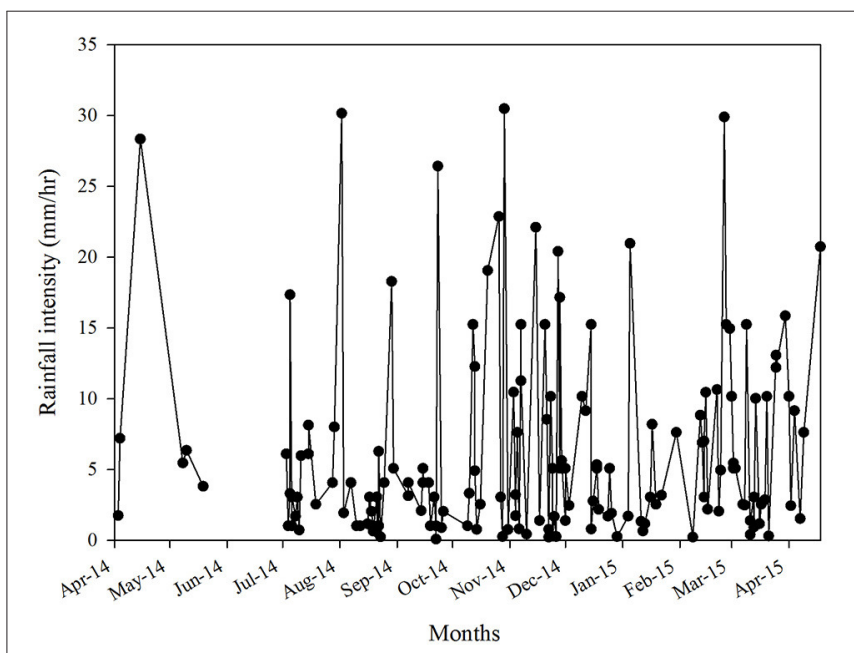

FIGURE 11 | Variations of rainfall intensity $(\mathrm{mm} / \mathrm{h})$ in Culebra Island during study period 2014-2015.

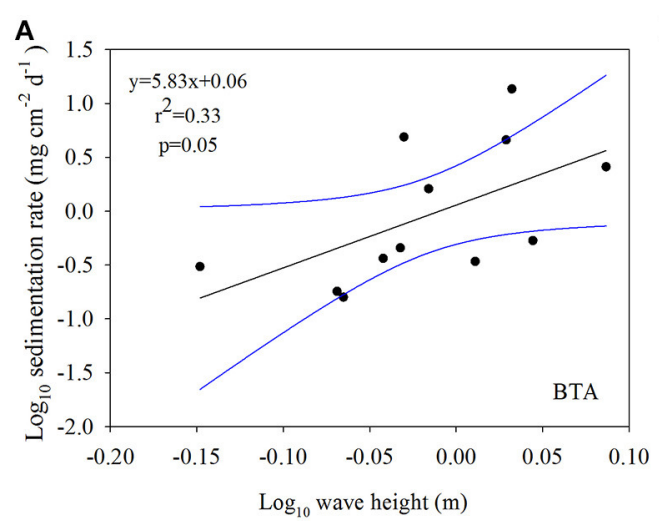

- $95 \%$ Confidence Band

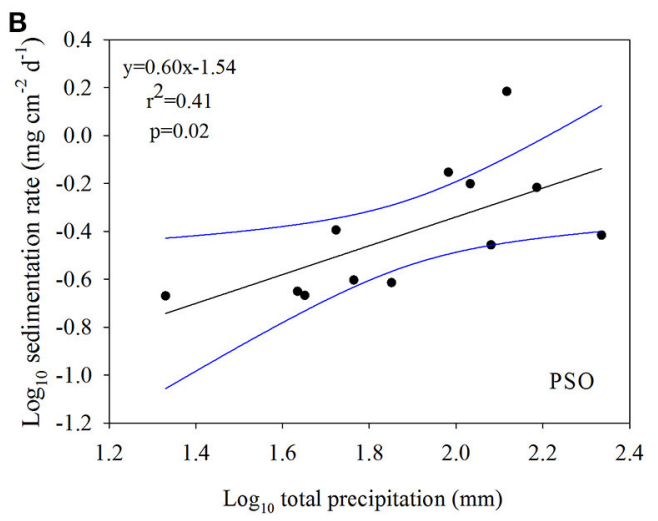

FIGURE 10 | Linear regression of sedimentation rate with total precipitation at BTA (A) and PSO (B). Blue line is $95 \%$ confidence interval band. 
dynamics, including terrigenous, fine sediment deposition, coarser sediment resuspension, and bedload transport.

Sediment accumulation rate along near-shore reefs varied from 0.15 to $37 \mathrm{mg} \mathrm{cm}^{-2} \mathrm{~d}^{-1}$ throughout the study period of 2014-2015. There were significant differences between distance zones factors and among time series. In both sites, coral reef closer to shore $(<60 \mathrm{~m})$ had the highest sedimentation and terrigenous accumulation rate. Sedimentation rates documented in Culebra Island were similar to previous field studies carried out in Puerto Rico, ranging from 3 to $30 \mathrm{mg} \mathrm{cm}^{-2} \mathrm{~d}^{-1}$ (Rogers, 1983), 3 to $13 \mathrm{mg} \mathrm{cm}{ }^{-2} \mathrm{~d}^{-1}$ (Hernández-Cruz et al., 2009), and at St. John (US Virgin Island, sedimentation rates ranged from 1 to $16 \mathrm{mg} \mathrm{cm} \mathrm{cm}^{-1}$ (Edmunds and Gray, 2014) during normal conditions. Healthy coral reefs have been suggested to have sedimentation rates of $<10 \mathrm{mg} \mathrm{cm}^{-2}$ $\mathrm{d}^{-1}$, meanwhile areas exposed to higher rates can have from moderate to severe impacts if they exceeded $50 \mathrm{mg} \mathrm{cm}^{-2} \mathrm{~d}^{-1}$ (Pastorok and Bilyard, 1985; Rogers, 1990). Sampling periods with major sediment and terrigenous accumulation pulses were associated with meteorological events that produced total rainfall higher than $30 \mathrm{~mm}$ (Figure 3), and individual rainfall intensity higher than $15 \mathrm{~mm} / \mathrm{h}$ (Figure 11). Studies conducted on St. John, US Virgin Islands, coastal sedimentary records suggest that runoff and terrigenous sediment input to marine coastal environments runoff were associated to rainfall events that exceed threshold of $\sim 12 \mathrm{~mm} /$ day (Brooks et al., 2015; Larson et al., 2015). Nevertheless, field studies have also shown that rainfall of just $3-5 \mathrm{~mm}$ can produce significant runoff and sediment transport from unpaved roads to coastal waters (Ramos-Scharrón and MacDonald, 2007). This suggests that weather conditions and land use patterns, at watershed and subwatershed spatial scales, can play a significant role in affecting coastal sediment dynamics. During the month of February 2015, a cold front that impacted the Caribbean region produced a total rainfall of $119 \mathrm{~mm}$ and wave height of up to $2.11 \mathrm{~m}$ which generated a high sedimentation rate at BTA (Figure 2) and exceeded the sedimentation rate threshold of $10 \mathrm{mg} \mathrm{cm}^{-2}$ $\mathrm{d}^{-1}$ suggested by Rogers (1990). Rogers (1990) validated the link between this sedimentation threshold and corals reef stress signs. In addition, nearshore coral reef degradation and spatial variation in sedimentation patterns have been widely associated with significant changes in land use at adjacent watersheds (Fabricius, 2005; Smith et al., 2008; Storlazzi et al., 2009; Wolanski et al., 2009; Risk and Edinger, 2011; Bartley et al., 2014; Hernández-Delgado et al., 2014a; Bégin et al., 2016).

The threats associated to unsustainable development of coastal watersheds are prompted by the increasing trend of urban expansion, deforestation, and exposure of bare soil, that increases the potential of soil erosion and sediment-laden runoff during pulse rainfall episodes (López et al., 1998; Fu et al., 2010; Ramos-Scharrón et al., 2012, 2015). Other persistent threats are caused by tourism-related activities at sensitive areas and steep slopes which are highly prone to erosion (Nemeth and Sladek, 2001; Hernández-Delgado et al., 2012, 2014a). In addition, the increasing number of beach visitors and recreational snorkelers could contribute to silt-clay sediment resuspension and impact sensitive coral reef habitats (Webler and Jakubowski, 2016). Throughout the last years, BTA coastal sub-watersheds and its main beach have been subjected to an increase in visitors and at the same time they have become more vulnerable to anthropogenic alteration of coastal areas by deforestation and bare soil exposure. In August 2013, watershed best management practices (i.e., bio-filters and reforestation) were implemented in Tamarindo Beach to address storm-water runoff impacts from an unpaved parking area $\left(160 \mathrm{~m}^{2}\right)$ as it represented one of the main drainage outlets and terrestrial sediment input to BTA (ViqueiraRíos et al., 2013; Sturm et al., 2014). Other temporary smallscale mitigation practices (i.e., silt fences) were implemented at upland gully erosion and drainage outlet near to coral reef and seagrass areas, but they had a very limited effect due to their restricted spatial scale and lack of adequate maintenance. The sediments that accumulated along BTA reefs had a proportion of fine, silt-clay $(<63 \mu \mathrm{m})$ that reached up to $45 \%$ during storm seasons. Silt-clay $(<63 \mu \mathrm{m})$ sediment deposition in BTA reached up to $45 \%$ during storm pulse events. Silt-clay sediment proportion had a significant relationship with total rainfall and rainfall intensity, suggesting that deposition of land-derived sediments is largely affected by local precipitation patterns. It implies that there is a meaningful interconnectivity between watershed condition, land uses, management, and terrestrial sediment impact to near-shore coral reefs largely magnified by pulse events.

A recent study concluded that PSO area had the lowest sediment yield values in Culebra Island (Ramos-Scharrón et al., 2012). However, during the study period the proportion of silt-clay increased $(>50 \%)$ subsequent to drastic changes in land-based activities due to an extensive deforestation event (April 2014) of a primary cacti forest located at a steep area for establishing illegal recreational campgrounds, which led to cliff erosion and increased sediment influx to PSO coral reef site (Hernández-Delgado et al., 2014a). During extreme rainfall events, trap accumulation of fine sediments extended to distance zone $\mathrm{B}(>60 \mathrm{~m})$ and silt-clay proportion reached values of up to $94 \%$. These results suggest that significant changes in coastal land use at individual watershed scales can affect delivery of fine sediments and impact coral reefs through large spatial scales $(>120 \mathrm{~m})$. Fine silts and clays have the ability to remain suspended in the water for prolonged periods of time and can be transported long distances by wind and wave-induced currents (Torres and Morelock, 2002; Hernández-Cruz et al., 2009; Davidson-Arnott, 2010; Fabricius, 2011; Bartley et al., 2014; Edmunds and Gray, 2014). Thus, fine sediments tend to have a major effect on light availability as they tend to be easily suspended by water turbulence and undergo repeated cycles of deposition and resuspension (Fabricius, 2005). Our results validate the relationship between land use patterns at the watershed spatial scale, weather and oceanographic conditions on influencing terrestrial-based sediment dynamics.

Our results suggest that changes on the local oceanographic dynamics can also play a significant role on sediment distribution along coastal coral reefs. Overall, wave height and dominant wave period were the main oceanographic forces that combined with rainfall to drive sediment distribution. These patterns were 
consistent with increased sediment accumulation across the wider Caribbean due to seasonal variation in wave energy by storms and swell events (Edmunds and Gray, 2014). Sediment texture analysis demonstrated that the proportion of sand ( $>63$ $\mu \mathrm{m})$ was greater at BTA reef $(>60 \%)$ throughout the study period. The statistically significant relationship between sand and wave height $\left(r^{2}=0.42, p=0.0227\right)$ indicates that coarse sediment collected in BTA was mostly influenced by resuspension and bedload transport. Likewise, it suggests that oceanographic dynamics can particularly affect coarse sediment resuspension and bedload transport. Sand sediments and $\mathrm{CaCO}_{3}$ deposit at closer distances to the source, so their transport is mainly driven alongshore and thus resuspension and vertical particle velocities can be limited to periods with strong wave action and swells (Davidson-Arnott, 2010; Van der et al., 2013). Reef bathymetry and depth contour gradient might have also a main role on the generation of wind-induced wave action and near bed shear stress at shallow areas that cause sediment resuspension, as evidenced by differences in sediment texture between sites and distance zones (Ogston et al., 2004; Zou et al., 2006; Storlazzi et al., 2009). Furthermore, this phenomenon is triggered by the ability of fine sediments to deposit between large particles on heterogeneous substrates, since the coarser sediment particles remain more exposed and can be easily resuspended during events of strong water turbulence (Van der et al., 2013).

In both sites, the largest variation in sediment composition was caused by terrigenous material and $\mathrm{CaCO}_{3}$, with a mean proportion of $45 \%$ for both constituents. This value is higher than previously documented terrigenous content of $22 \%$ from sediment samples collected in coral reefs at southwestern PR (Hernández-Cruz et al., 2009). In contrast, our values were lower than terrigenous content reported from other Caribbean regions, with documented values ranging from 72 to $96 \%$ at Saba, from 16 to $87 \%$ at St. Lucia (Bégin et al., 2013). However, both islands are larger in size, have steeper slopes and larger catchment areas, and rainfall is much higher than in Culebra Island. There is a general trend of decreasing terrigenous material with distance from source. The $\mathrm{CaCO}_{3}$ is a biogenic constituent as it originates from bioerosion of corals and coralline algae, as well as there is direct contribution from organisms with $\mathrm{CaCO}_{3}$ skeletons, which can be found both in sand and silt-clay grain size fractions (Hubbard et al., 1992; Brooks et al., 2007; HernándezCruz et al., 2009; Wolanski et al., 2009). The $\mathrm{CaCO}_{3}$ content on sediments was slightly homogenous along both reefs and it could be hypothesized that nearshore coral reefs may be experiencing similar bioerosion trends at broad spatial scales. Bioerosion might be accelerated by eutrophication (Glynn, 1997; Holmes, 2000). The proximity of coastal reefs to potential eutrophication sources can increase their vulnerability to bioerosion. This is a subject that should be further assessed to understand the reefs $\mathrm{CaCO}_{3}$ production and sinking by component (i.e., coralline algae, coral calcification), and to determine the overall effects of increasing SST and ocean acidification due to climate change on carbonate sediment cycling (Hubbard et al., 1992; De Bakker et al., 2016). The organic matter content is the lowest constituent in marine sediment and it has been repeatedly documented
(Torres and Morelock, 2002; Brooks et al., 2007; HernándezCruz et al., 2009; Bégin et al., 2016). Our analysis demonstrated that organic matter represented $<10 \%$ of the total sediment composition. The significant relationship between organic matter and SST can be related to the capability of higher temperature to support organic matter degradation by microbial communities (Arndt et al., 2013).

Sedimentation complements the multiplicity of regional and local stressors that contribute to coral reef decline. It often represents a stochastic stress event and a threat to the health and biodiversity of near-shore coral reefs. This study revealed that even in small tropical semi-arid islands sedimentation associated to rainfall pulses is a recurrent stress, which is linked to local land uses, and to meteorological and oceanographic dynamics. Sedimentation can be identified as a rapidly increasing threat to coral reefs with projected increases in the frequency and severity of extreme weather events, especially intense rainfall after long periods of dry conditions, as a direct consequence of climate change (Giannini et al., 2000; Meehl et al., 2007; Campbell et al., 2011; Beharry et al., 2015). Changing climate trends might also represent an increase in recurrence of terrestrial sediment input to coastal waters, thus leading to chronic states and decline of near-shore coral reefs worldwide. Therefore, as climate variability is projected to continue intensifying across larger spatial and temporal scales (Easterling et al., 2000), there is a need of long-term monitoring of land-sea interactions through coastal-marine sediment distribution to understand the threat it might represent toward endangered coral species, and benthic communities, fostering the long-term degradation of ecosystem functions. Future research could aim to assess sedimentary records through sediment core analyses to identify since when anthropogenic alterations of coastal watersheds have impacted spatial and temporal trends of terrigenous sediment deposition on the marine environment and the combined effects of climatic variation. In addition, assessment of mineralogical composition of surficial marine sediments could assist to identify point sources at the watershed and island-scales, and needs further monitoring.

A possible limitation of the study was the physical and meteorological conditions experienced during study period, which were characterized by an extended period of drought during summer season that altered the original projected sampling time frame, and prevented sampling of more extreme rainfall events. Extreme events were limited to winter and spring season with combined conditions of strong rainfall and wave energy, main forces that produce terrestrial sediment influx to coastal waters followed by resuspension of bottom sediments. These mixed conditions represented a limitation to distinguish the main sources of sedimentation. In Culebra Island there is a lack of permanent meteorological stations to provide easy access to detailed 15-min intervals weather conditions, and the existing buoy was more representative of open ocean conditions, since it is located about $10-15 \mathrm{~km}$ from the coast. Future research should take into account the need of downscaling local environmental, weather and oceanographic data for accurate analysis, modeling, and to contribute valuable information for coral reef conservation and ecosystem restoration strategies. 
The nearshore coral reefs surrounding small islands need an integrated and holistic management approach to conserve and rehabilitate ecosystem resilience and functions, including:

- Long-term commitment of stakeholders (community-based, natural resources managers, academia) to cope with future trends of climate variability, following ecosystem-based management principles.

- Design and implement integrated and adaptive coastal management strategies that address coastal maritime zone and watershed management needs in order to reduce soil erosion and sediment delivery at the watershed and sub-watershed scales, and reduce runoff impacts to adjacent sensitive habitats, such as coral reefs.

- Reduce local stressors that are threatening the viability of coral reef restoration efforts. Strong evidence has already showed that recurrent extreme rainfall events and storm-associated impacts are a major threat for the success of coral farming and reef restoration efforts (Hernández-Delgado et al., 2014a). Efforts need to be taken to reduce or eliminate major sources of soil erosion and sediment delivery stress.

- It is essential to assess sediment fluxes before, during and after implementation of watershed best management and restoration practices in order to be able to identify the short-term outcomes of erosion control practices along nearshore coral reefs, and to use the generated information to accurately anticipate long-term implications for coral reef benthic communities.

- These holistic approaches also need the support and enforcement of environmental, land-use, and protected area regulations, promote the use and integration of data generated through participatory citizen science and academia into management, decision making processes, and prioritize the need of collaborative actions that promote sustainable restoration and conservation initiatives at the watershed and coral reef scales to prevent further degradation of already threatened coral reefs.

Spatial and temporal sedimentation dynamics along near-shore coral reefs are linked to land-sea and climate interactions. Our results highlight the existing interactions among land use patterns, coastal watershed conservation, and management on its direct influence on sediment supply, distribution, and sedimentation stress to nearshore coral reefs. Our results point out five main conclusions: (1) Human alteration of sensitive, highly erodible watersheds adjacent to coastal areas influence the amount, extent and recurrence of terrestrial sediment stress to near-shore coral reefs; (2) Local climate has a significant effect on terrestrial sediment input and distribution, even on semiarid islands, since total rainfall and intensity, and rainfall pulse events are the main driving forces of sedimentary dynamics at watershed scales; (3) Sediment texture, sand and silt-clay grain size fractions, and sediment composition along nearshore marine environments vary according to local climate and oceanographic conditions. Wave height and dominant wave period determine sediment resuspension and bedload transport; (4) Reef zones closer to shore $(<60 \mathrm{~m})$ are more exposed to sedimentation stress, and vulnerable to changing sediment dynamics, including fine silt-clay sediments and terrigenous sediment deposition. During doldrum conditions fine sediments tend to remain suspended for prolonged periods of time and it thus may represent broader impact into marine ecosystems across larger spatial scales $(>60 \mathrm{~m})$, mostly depending on climate and local oceanographic dynamics; and (5) As a consequence, terrestrial sediments were identified as the main constituent of marine sediments, representing a major threat to coral reefs and associated ecosystems at extended spatial and temporal scales. The extent to which climate-related changes influence local weather, which could result in increased frequency and severity of extreme weather events, combined with unsustainable land use practices and the lack of watershed conservation practices, may increase the long-term adverse impacts of sediment delivery to coral reefs. Therefore, the need of implementing a participatory approach which aims to achieve integrated management of coastal watersheds, coral reefs, and other benthic habitats is emphasized. This is a fundamental step toward identifying and implementing effective collaborative actions and adaptive management strategies to reduce land-based threats, reverse coral reef decline, and recover ecosystem and structural resilience. Furthermore, decision-making processes should make adequate use of science-based information that advance understanding of terrestrial and marine ecosystem interconnectivity to implement watershed and coral reefs management plans and restore degraded habitats. Integrated ecosystem-based management can provide an adequate framework to implement concerted efforts, such as sustainable land use practices, coastal and marine ecosystem rehabilitation, outreach, and conservation strategies aimed at maximizing ecological integrity and resilience of coral reefs worldwide.

\section{AUTHOR CONTRIBUTIONS}

Conceived and designed study: AO, AM, and EH-D. Field sampling and analysis: AO, AM, VT, and EH-F. Analyzed the data: AO, VT, and EH-D. Wrote the paper: AO, AM, and EH-D.

\section{FUNDING}

This study was possible by partial funding provided by CATEC NSF-HDR-0734826, University of Puerto Rico's Central Administration through CATEC to EH-D, and by the University of Puerto Rico's, Río Piedras Campus, Deanship of Graduate Studies and Research.

\section{ACKNOWLEDGMENTS}

The authors thank the Coral Reef Research Group of the Center of Applied Tropical Ecology and Conservation (CATEC), University of Puerto Rico, volunteers from the student's chapter of NGO Sociedad Ambiente Marino (CESAM), and Elizabeth Benson, intern from Harvard University, for their continuous 
and enthusiastic assistance with sediment sample collection and analyses. We thank CATEC for partially supporting this project, as well as Dr. Elvira Cuevas and Larry Díaz, for the advice, support and assistance on sediment sample analyses, and for providing access to materials and laboratory facilities. Support was also provided by the Department of Environmental Sciences, the Institute for Tropical Ecosystem Studies, and by Dr. Jorge Ortiz-Zayas, who provided access to materials and laboratory facilities. Our deepest gratitude to Samuel E. Suleiman-Ramos

\section{REFERENCES}

Anderson, M. (2001). Permutation tests for univariate or multivariate analysis of variance and regression. Can. J. Fish. Aquat. Sci. 58, 626-639. doi: 10.1139/f01-004

Anderson, M., Gorley, R., and Clarke, K. (2008). PERMANOVA+ for PRIMER: Guide to software and Statistical Methods. Plymouth: PRIMER-E.

Apitz, S. (2012). Conceptualizing the role of sediment in sustaining ecosystem services: sediment-ecosystem regional assessment (SEcoRA). Sci. Tot. Environ. 415, 9-30. doi: 10.1016/j.scitotenv.2011.05.060

Arndt, S., JØrgensen, B., LaRowe, D., Middelburg, J., Pancost, R., and Regnier, P. (2013). Quantifying the degradation of organic matter in marine sedments: a review and synthesis. Earth Sci. Rev. 123, 53-86. doi: 10.1016/j.earscirev.2013.02.008

Barbier, E., Hacker, S., Kennedy, C., Koch, E., Stier, A., and Silliman, B. (2011). The value of marine and coastal ecosystem services. Ecol. Monogr. 81, 169-193. doi: 10.1890/10-1510.1

Bartley, R., Bainbridge, Z., Lewis, S., Kroon, F., Wilkinson, S., Brodie, J., et al. (2014). Relating sediment impacts on coral reefs to watershed sources, processes and management: a review. Sci. Tot. Environ. 468-469, 1138-1153. doi: 10.1016/j.scitotenv.2013.09.030

Bégin, C., Nugues, N., Hawkins, J., Roberts, C., and Côte, I. (2016). Effects of protection and sediment stress on coral reefs in Saint Lucia. PLoS ONE 11:e0146855. doi: 10.1371/journal.pone. 0146855

Bégin, C., Wurzbacher, J., and Côte, I. (2013). Variation in benthic communities of eastern Caribbean coral reefs in relation to surface sediment composition. Mar. Biol. 160, 343-353. doi: 10.1007/s00227-012-2092-5

Beharry, S. L., Clarke, R. M., and Kumarsingh, K. (2015). Variations in extreme temperature and precipitation for a Caribbean island: Trinidad. Theor. Appl. Climatol. 122, 783-797. doi: 10.1007/s00704-014-1330-9

Bengtsson, L., and Enell, M. (1986). "Chemical analysis," in Handbook of Holocene Palaeoecology and Palaeohydrology, ed B. Berglund (Chichester: John Wiley \& Sons Ltd.), 423-451.

Brooks, G., Devine, B., Larson, R., and Rood, B. (2007). Sedimentary development of Coral Bay, St. John, USVI: a shift from natural to antropogenic influences. Caribb. J. Sci. 43, 226-243. doi: 10.18475/cjos.v43i2.a8

Brooks, G. R., Larson, R. A., Devine, B., and Schwing, P. T. (2015). Annual to millennial record of sediment delivery to US Virgin Island coastal environments. Holocene 25, 1015-1026. doi: 10.1177/0959683615 575357

Browning, T., Sawyer, D., Larson, R., O’Donnell, B., Hadfield, J., and Brooks, G. (2016). Linking Land \& Sea: watershed Evaluation and Mineralogical Distribution of Sediments in Eastern St John, USVI. Caribb. J. Sci. 49, 38-56. doi: 10.18475/cjos.v49il.a5

Campbell, J., Taylor, M., Stephenson, T., Watson, R., and Whyte, F. (2011). Future climate of the Caribbean from a regional climate model. Int. J. Climatol. 31, 1866-1878. doi: 10.1002/joc.2200

Chariton, A., Pettigrove, V., and Baird, D. (2016). "Ecological assessment," in Sediment Quality Assessment: A Practical Guide, eds S. Simpson and G. Batley (Clayton South, VIC: CSIRO), 195-228.

Clarke, K., and Ainsworth, M. (1993). A method of linking multivariate community structure to multivariate science. Mar. Ecol. Progr. Ser. 92, 205-219. doi: $10.3354 /$ meps092205 and all the members of Sociedad Ambiente Marino, and to Mary Ann Lucking from CORALations for providing lodging and logistic support.

\section{SUPPLEMENTARY MATERIAL}

The Supplementary Material for this article can be found online at: http://journal.frontiersin.org/article/10.3389/fmars. 2017.00249/full\#supplementary-material

Clarke, K., Gorley, R., Somerfield, P., and Warwick, R. (2014). Changes in Marine Communities: An Approach to Statistical Analysis and Interpretation, 3rd Edn. Plymouth: PRIMER-E.

Cortés, J., and Risk, M. (1985). A reef under siltation stress: Cahuita, Costa Rica. Bull. Mar. Sci. 36, 339-356.

Davidson-Arnott, R. (2010). "Coastal sediment transport”, in Introduction to Coastal Processes and Geomorphology (New York, NY: Cambridge University Press), 139-176.

DNER (2013). Local Action Strategies (LAS) for Coral Reef Conservation 2011-2015. San Juan: Puerto Rico Department of Natural and Environmental Resources.

De Bakker, D. M., Meesters, E. H., Bak, R. P., Nieuwland, G., and Van Duyl, F. C. (2016). Long-term shifts in coral communities on shallow to deep reef slopes of curacao and bonaire: are there any winners? Front. Mar. Sci. 3:247. doi: 10.3389/fmars.2016.00247

Easterling, D., Meehl, G., Parmesan, C., Changnon, S., Karl, T., and Mearns, L. (2000). Climate extremes: observations, modeling and impacts. Science 289, 2068-2074. doi: 10.1126/science.289.5487.2068

Edmunds, P., and Gray, S. (2014). The effects of storms, heavy rains and sedimentation on the shallow coral reefs in St. John, US Virgin Islands. Hydrobiologia 734, 143-158. doi: 10.1007/s10750-014-1876-7

Fabricius, K. (2005). Effects of terrestrial runoff on the ecology of corals and coral reefs: review and synthesis. Mar. Pollut. Bull. 50, 125-146. doi: 10.1016/j.marpolbul.2004.11.028

Fabricius, K. (2011). "Factors determining the resilience of coral reefs to eutrophication: a review and conceptual model," in Coral Reefs: An Ecosystem in Transition, eds Z. Dubinsky and N. Stambler (London; New York, NY: Springer), 493-505.

Folk, R. (1974). Petrology of Sedimentary Rocks. Austin, TX: Hemphill Publishing Company.

Fu, B., Newham, L., and Ramos-Scharrón, C. (2010). A review of surface erosion and sediment delivery models for unsealed roads. Environ. Modell. Softw. 25, 1-14. doi: 10.1016/j.envsoft.2009.07.013

Gardner, T., Côte, I., Gill, J., Grant, A., and Watkinson, A. (2003). Longterm region-wide decline in caribbean corals. Science 301, 958-960. doi: $10.1126 /$ science. 1086050

Gellis, A. (2013). Factors influencing storm-generated suspended-sediment concentrations and loads in four basins of contrasting land use, humidtropical Puerto Rico. Catena 104, 39-57. doi: 10.1016/j.catena.2012. 10.018

Giannini, A., Kushnir, Y., and Cane, M. (2000). Interannual variability of caribbean rainfall, ENSO, and the Atlantic Ocean. J. Climate 13, 297-311. doi: 10.1175/1520-0442(2000)013<0297:IVOCRE>2.0.CO;2

Glynn, P. W. (1997). "Bioerosion and coral-reef growth: a dynamic balance," in Life and Death of Coral Reefs, ed C. Birkeland (New York, NY: Chapman and Hall), 68-95.

Gotelli, N., and Ellison, A. (eds.). (2013). "Managing and curating data," in A Primer of Ecological Statistics (Sunderland, MA: Sinauer Associates), 208-235.

Gower, J. (1966). Some distance properties of latent root and vector methods used in multivariate analysis. Biometrika 53, 325-338. doi: 10.1093/biomet/53.3-4.325

Gray, S. (2012). A Comparative Analysis of Sedimentation and Water Quality in Mangrove, Shore, Bay and Reef Environments below a Developed vs an Undeveloped Watershed, St. John, US Virgin Island. Technical Report. Fisheries Habitat Conservation Program Office NOAA. 
Heiri, O., Lotter, A., and Lemcke, G. (2001). Loss on ignition as a method for estimating organic and carbonate content in sediments: reproducibility and comparability of results. J. Paleolimnol. 25, 101-110. doi: 10.1023/A:1008119611481

Hernández-Cruz, R., Sherman, C., Weil, E., and Yoshioka, P. (2009). Spatial and temporal patterns in reef sediment accumulation and composition, southwestern insular shelf of PR. Caribb. J. Sci. 2-3, 138-150. doi: $10.18475 /$ cjos.v45i2.a3

Hernández-Delgado, E. A (2000). Effects of Anthropogenic Stress Gradients in the Structure of Coral Reef Epibenthic and Fish Communities. Ph.D. dissertation, Department of Biology, University of Puerto Rico, San Juan.

Hernández-Delgado, E. A (2003). Suplemento Técnico al PLAN de Manejo de la Reserva Natural del Canal Luis Pe-a, Culebra, Puerto Rico. I. Caracterización de habitáculos. Informe Técnico. Departamento de Recursos Naturales y Ambientales. San Juan.

Hernández-Delgado, E. A. (2015). The emerging threats of climate change on tropical coastal ecosystem services, public health, local economies and livelihood sustainability of small islands: cumulative impacts and synergies. Mar. Pollut. Bull. 101, 5-28. doi: 10.1016/j.marpolbul.2015.09.018

Hernández-Delgado, E. A., Hutchinson-Delgado, Y., Laureano, R., HernándezPacheco, R., Ruiz-Maldonado, T., Oms, J., et al. (2011). "Sediment stress, water turbidity and sewage impacts on threatened Elkhorn coral (Acropora palmata) stands at Vega Baja, Puerto Rico," in Proceedings of the Gulf and Caribbean Fisheries Institute, Vol. 63 (Ft. Pierce, FL), 83-92.

Hernández-Delgado, E. A., Medina, J., Ortiz, V., Mas, M., Marrero, P., Mattei, H., et al. (2009). Biological Characterization of Shallow-Water Coral Reef Communities across a Water Quality Gradient within the Luis Pe-a Channel Natural Reserve, Culebra Island, Puerto Rico. Final Technical Report, Department of Natural and Environmental Resources, Public Health Graduate School, University of Puerto Rico-Medical Science Campus and Department of Natural and Environmental Resources, San Juan.

Hernández-Delgado, E. A., Mercado-Molina, A., Alejandro-Camis, P., CandelasSánchez, F., Fonseca-Miranda, J., González-Ramos, C., et al. (2014a). Community-based coral reef rehabilitation in a changing climate: lessons learned from Hurricanes, extreme rainfall, and changing land use impacts. Open J. Ecol. 4, 918-944. doi: 10.4236/oje.2014.414077

Hernández-Delgado, E. A., Montañez-Acuña, Otaño-Cruz, A., and SuleimánRamos, S. (2014b). Bomb-cratered coral reefs in Puerto Rico, the untold story about a novel habitat: from reef destruction to community-based ecological rehabilitation. Rev. Biol. Trop. 62, 183-2000. doi: 10.15517/rbt.v62i0. 15913

Hernández-Delgado, E. A., Ramos-Scharrón, C. E., Guerrero, C., Lucking, M. A., Laureano, R., Méndez-Lázaro, P. A., et al. (2012). "Long-term impacts of tourism and urban development in tropical coastal habitats in a changing climate: lessons learned from Puerto Rico," in Visions from Global Tourism Industry-Creating and Sustaining Competitive Strategies, ed M. Kasimoglu (Rijeka: InTech Publications), 357-398. doi: 10.5772/38140

Holmes, K. (2000). Effects of eutrophication on bioeroding sponge communities with the description of new West Indian Sponges, Cliona spp. (Porifera: Hadromerida: Clionidae). Invert. Biol. 119, 125-138. doi: 10.1111/j.1744-7410.2000.tb00001.x

Hubbard, D., Miller, A., and Scaturo, D. (1992). Production and cycling of calcium carbonate in a shelf-edge reef system (St. Croix, U.S. Virgin Islands): applications to the nature of reef systems in the fossil record. J. Sediment. Petrol. 60, 335-360.

Hughes, T. (1994). Catastrophes, phase shifts, and large scale degradation of a Caribbean coral reef. Science 265, 1547-1551. doi: $10.1126 /$ science.265.5178.1547

Hughes, T., Graham, N., Jackson, J., Mumby, P., and Steneck, R. (2010). Rising the challenge of sustaining coral reef resilience. Trends Ecol. Evol. 25, 633-642. doi: 10.1016/j.tree.2010.07.011

Jackson, J., Donovan, M., Cramer, K., and Lam, W. (eds.). (2014). Status and Trends of Caribbean Coral Reefs: 1970-2012. Gland: Global Coral Reef Monitoring Network, IUCN.

Larson, R., Brooks, G., Devine, B., Schwing, P., Holmes, C., Jilbert, T., et al. (2015). Elemental signature of terrigenous sediment runoff as recorded in coastal salt ponds: US Virgin Islands. Appl. Geochem. 63, 573-585. doi: 10.1016/j.apgeochem.2015.01.008
López, T., Aide, M. T., and Scatena, F. N. (1998). The effect of land use on soil erosion in the Guadiana Watershed in Puerto Rico. Caribb. J. Sci. 34, 298-307.

Loya, Y. (1976). Effects of water turbidity and sedimentation on the community structure of Puerto Rican Corals. Bull. Mar. Sci. 26, 450-466.

Meehl, G., Stocker, T., Collins, W., Friedlingstein, P., Gaye, A., Gregory, J., et al. (2007). Global Climate Projections. In: Climate Change 2007: The Physical Science Basis. Contribution of Working Group I to the Fourth Assessment Report of the Intergovernmental Panel on Climate Change. Cambridge University Press, Cambridge; New York, NY.

Moberg, F., and Folke, C. (1999). Ecological goods and services of coral reef ecosystems. Ecol. Econ. 29, 215-233. doi: 10.1016/S0921-8009(99)00009-9

Nemeth, R. S., and Sladek, J. N. (2001). Monitoring the effects of land development on the near-shore reef environments of St. Thomas, USVI. Bull. Mar. Sci. 69, 759-775. Available online at: http://www.ingentaconnect.com/content/ umrsmas/bullmar/2001/00000069/00000002/art00041

Nugues, M., and Roberts, C. (2003). Partial Mortality in massive reef corals as an indicator of sediment stress on coral reefs. Mar. Pollut. Bull. 46, 314-323. doi: 10.1016/S0025-326X(02)00402-2

Ogston, A., Presto, M., Storlazzi, C., and Field, M. (2004). Sediment resuspension and transport patterns on a fringing reef flat, Molokai, Hawaii. Coral Reefs 23, 559-569. doi: 10.1007/s00338-004-0415-9

Pastorok, R., and Bilyard, G. (1985). Effects of sewage pollution on coral-reef communities. Mar. Ecol. Progr. Ser. 21, 175-189. doi: 10.3354/meps021175

Ramos-Scharrón, C. E., Amador, J. M., and Hernández-Delgado, E. A. (2012). "An interdisciplinary erosion mitigation approach for coral reef protection a case study from the eastern Caribbean," in Marine Ecosystems, ed A. Cruzado (Rijeka: InTech Publications), 127-160. doi: 10.5772/35709

Ramos-Scharrón, C., and MacDonald, L. (2007). Development and application of GIS-based sediment budget model. J. Environ. Manage. 84, 157-172. doi: 10.1016/j.jenvman.2006.05.019

Ramos-Scharrón, C., Torres-Pulliza, D., and Hernández-Delgado, E. (2015). Watershed- and island wide- scale land cover changes in Puerto Rico (19302004) and their potential effects on coral reef ecosystems. Sci. Tot. Environ. 506-507, 241-251. doi: 10.1016/j.scitotenv.2014.11.016

Richmond, R. (1997). "Reporduction and recruitment in corals: Critical links in the persistence of reefs," in Life and Death of Coral Reefs, ed C. Birkeland (New York, NY: Chapman and Hall), 175-197

Risk, M. J., and Edinger, E. (2011). "Impacts of sediment on coral reefs," in Encyclopedia of Modern Coral Reefs, ed D. Hopely (Dordrecht: Springer), 575-585.

Roberts, C., McClean, C., Veron, J., Hawkins, J., Allen, G., McAllister, D., et al. (2002). Marine biodiversity hotspots and conservation priorities for tropical reefs. Science 295, 1280-1284. doi: 10.1126/science.1067728

Rodrigues, J., Andrade, E., Queiroz, H., Ribiero, L., and Santos, J. (2013). Sediment loss in semiarid small watershed due to the land use. Revista Ciencia Agronomica 44, 488-498. doi: 10.1590/S1806-669020130003 00010

Rogers, C. (1983). Sublethal and lethal effects of sediments applied to common Caribbean Corals in the field. Mar. Pollut. Bull. 14, 378-382. doi: 10.1016/0025-326X(83)90602-1

Rogers, C. (1990). Response of coral reefs and reef organisms to sedimentation. Mar. Ecol. Progr. Ser. 62, 185-202. doi: 10.3354/meps0 62185

Rogers, C., Garisson, G., Grober, R., Hillis, Z., and Franke, M. (1994). Coral Reef Monitoring Manual for the Caribbean and Western Atlantic. National Park Service, Virgin Island National Park.

Smith, T., Nemeth, R., Blondeau, J., Calnan, J., Kadison, E., and Herzlieb, S. (2008). Assessing coral reef health across onshore to offshore stress gradient in the US Virgin Islands. Mar. Pollut. Bull. 53, 1983-1991. doi: 10.1016/j.marpolbul.2008.08.015

Storlazzi, C., Field, M., and Bothner, M. (2011). The use (and misuse) of sediment traps in coral reef environments: theory, observations, and suggested protocols. Coral Reef 30, 23-38. doi: 10.1007/s00338-010-0705-3

Storlazzi, C., Field, M., Bothner, M., Presto, M., and Draut, A. (2009). Sedimentation processes in a coral reef embayment: Hanalei Bay, Kauai. Mar. Geol. 264, 140-151. doi: 10.1016/j.margeo.2009.05.002

Sturm, P., Viqueira-Rios, R., Meyer-Comas, L., Hernández-Delgado, E., GonzálezRamos, C., Montañez-Acuña, et al. (2014). Culebra Community Watershed 
Action Plan for Water Quality and Coral Reefs. Technical Report Submitted to NOAA, Silver Spring, MD.

Torres, J., and Morelock, J. (2002). Effect of terrigenous sediment influx on coral cover and linear extension rates of three caribbean massive coral species. Caribb. J. Sci. 38, 222-229.

Van der, A., D., Ribberink, J., van der Werf, J., O’Donoghue, T., Buijsrogge, R., and Kranenburg, W. (2013). Practical sand transport formula for non-breaking waves and currents. Coast. Eng. 76, 26-42. doi: 10.1016/j.coastaleng.2013.01.007

Viqueira-Ríos, R., Meyer-Comas, L., and Sturm, P. (2013). Proyecto de Restauración Ambiental Playa Tamarindo Culebra, Puerto Rico, Fase, I. Reporte Técnico sometido a NOAA y DRNA.

Weber, M., Lott, C., and Fabricius, K. (2006). Sedimentation stress in a scleractinian coral exposed to terrestrial and marine sediments with contrasting physical, organic and geochemical properties. J. Exp. Mar. Biol. Ecol. 336, 18-32. doi: 10.1016/j.jembe.2006. 04.007

Webler, T., and Jakubowski, K. (2016). Mitigating damaging behaviors of snorkelers to coral reefs in Puerto Rico through a pre-trip media-based intervention. Biol. Conserv. 197, 223-228. doi: 10.1016/j.biocon.2016. 03.012

Wild, C., Hoegh-Guldberg, O., Naumann, M., Colombo-Pallota, F., Ateweberhan, M., Iglesias-Prieto, R., et al. (2011). Climate change impedes scleractinian corals as primary reef ecosystem engineers. Mar. Freshw. Res. 62, 205-215. doi: 10.1071/MF10254
Wilkinson, C., and Souter, D. (2008). Status of Caribbean Coral Reefs after Bleaching and Hurricanes in 2005. Global Coral Reef Monitoring Network, and Reef and Rainforest Research Center, Townsville, QLD, 152.

Wolanski, E., Martinez, J., and Richmond, R. (2009). Quantifying the impact of watershed urbanization on a coral reef: Maunalua Bay, Hawaii. Estuar. Coast. Shelf Sci. 84, 259-268. doi: 10.1016/j.ecss.2009.06.029

Zhang, X., Alexander, L., Hegerl, G. C., Jones, P., Tank, A. K., Peterson, T. C., et al. (2011). Indices for monitoring changes in extreme based on daily temperature and precipitation data. WIREs Climate Change 2, 851-870. doi: $10.1002 /$ wcc. 147

Zou, Q., Bowen, A. J., and Hay, A. E. (2006). Vertical distribution of wave shear stress in variable depth: theory and field observations. J. Geophys. Res. 111:C09032. doi: 10.1029/2005JC003300

Conflict of Interest Statement: The authors declare that the research was conducted in the absence of any commercial or financial relationships that could be construed as a potential conflict of interest.

Copyright (C) 2017 Otaño-Cruz, Montañez-Acuña, Torres-López, HernándezFigueroa and Hernández-Delgado. This is an open-access article distributed under the terms of the Creative Commons Attribution License (CC BY). The use, distribution or reproduction in other forums is permitted, provided the original author(s) or licensor are credited and that the original publication in this journal is cited, in accordance with accepted academic practice. No use, distribution or reproduction is permitted which does not comply with these terms. 